\title{
Structure-activity Relationships of Stemphones, Potentiators of Imipenem Activity against Methicillin-resistant Staphylococcus aureus
}

\author{
Hiroyuki Yamazaki, Nobuhiro Koyama, Satoshi Ōmura, Hiroshi Tomoda
}

Received: May 9, 2008 / Accepted: July 3, 2008

(C) Japan Antibiotics Research Association

\begin{abstract}
From a further purification study, four new stemphones $\mathrm{D}$ to $\mathrm{G}$ were isolated along with previously reported stemphones $\mathrm{B}$ and $\mathrm{C}$ from the culture broth of Aspergillus sp. FKI-2136. Twenty-one derivatives were semisynthetically prepared from stemphones C, E and G. Potentiation of imipenem activity against methicillinresistant Staphylococcus aureus (MRSA) by all the stemphones including natural and semisynthetic ones was compared to study the structure-activity relationships. Derivatives with a free hydroxy or an $O$-acyl residue having a $\mathrm{C} 2$ to $\mathrm{C} 5$ carbon length at $\mathrm{C}-4$ held the potentiating activity, but those with a longer acyl residue lost the activity. The presence of an oxo or a free hydroxy residue at C-10 is important for the potentiating activity because introduction of an alkyl or acyl residue at this position resulted in a loss of activity. Among them, stemphone $\mathrm{E}$ exhibited the most potent potentiation of imipenem activity against MRSA and the lowest cytotoxic activity against Jurkat cells.
\end{abstract}

Keywords stemphones, imipenem potentiator, methicillin-resistant Staphylococcus aureus, MRSA, fungal metabolite

\section{Introduction}

Methicillin-resistant Staphylococcus aureus (MRSA), a major and widespread pathogen in hospitals, has developed resistance to many other antibiotics $[1,2]$. It is therefore important and necessary to find new antimicrobial agents and to devise new measures that are effective against MRSA infection. During the course of our screening for potentiators of imipenem activity against MRSA from microorganisms, stemphones $\mathrm{B}$ and $\mathrm{C}$ (Fig. 1) were previously discovered from the culture broth of Aspergillus sp. FKI-2136 [3]. From further precise analysis of the culture broth, new stemphones D, E, F and G (Fig. 1) were discovered. Furthermore, twenty-one derivatives (Fig. 2) were prepared semisynthetically from stemphones C, E and G. In this study, isolation, structural elucidation of new stemphones, preparation of the derivatives and the structure-activity relationships are described.

\section{Materials and Methods}

\section{General Experimental Procedures}

Fungal strain Aspergillus sp. FKI-2136 was used for production of stemphones [3]. Stemphones B and C and cochlioquinone D were obtained from an 11-day old culture broth of Aspergillus sp. FKI-2136 as previously reported [3]. Stemphones D and E were obtained from the 7-day old culture broth, and stemphones $F$ and $G$ were from the 15day old culture broth as described below. For detection of stemphone analogs in culture broths, the samples (ethyl
H. Tomoda (Corresponding author), H. Yamazaki, N. Koyama: School of Pharmacy, Kitasato University, 5-9-1 Shirokane, Minato-ku, Tokyo 108-8641, Japan,

E-mail: tomodah@pharm.kitasato-u.ac.jp
S. Ömura: Kitasato Institute for Life Sciencs and Graduate School of Infection Control Sciences, Kitasato University, 5-9-1 Shirokane, Minato-ku, Tokyo 108-8641, Japan 

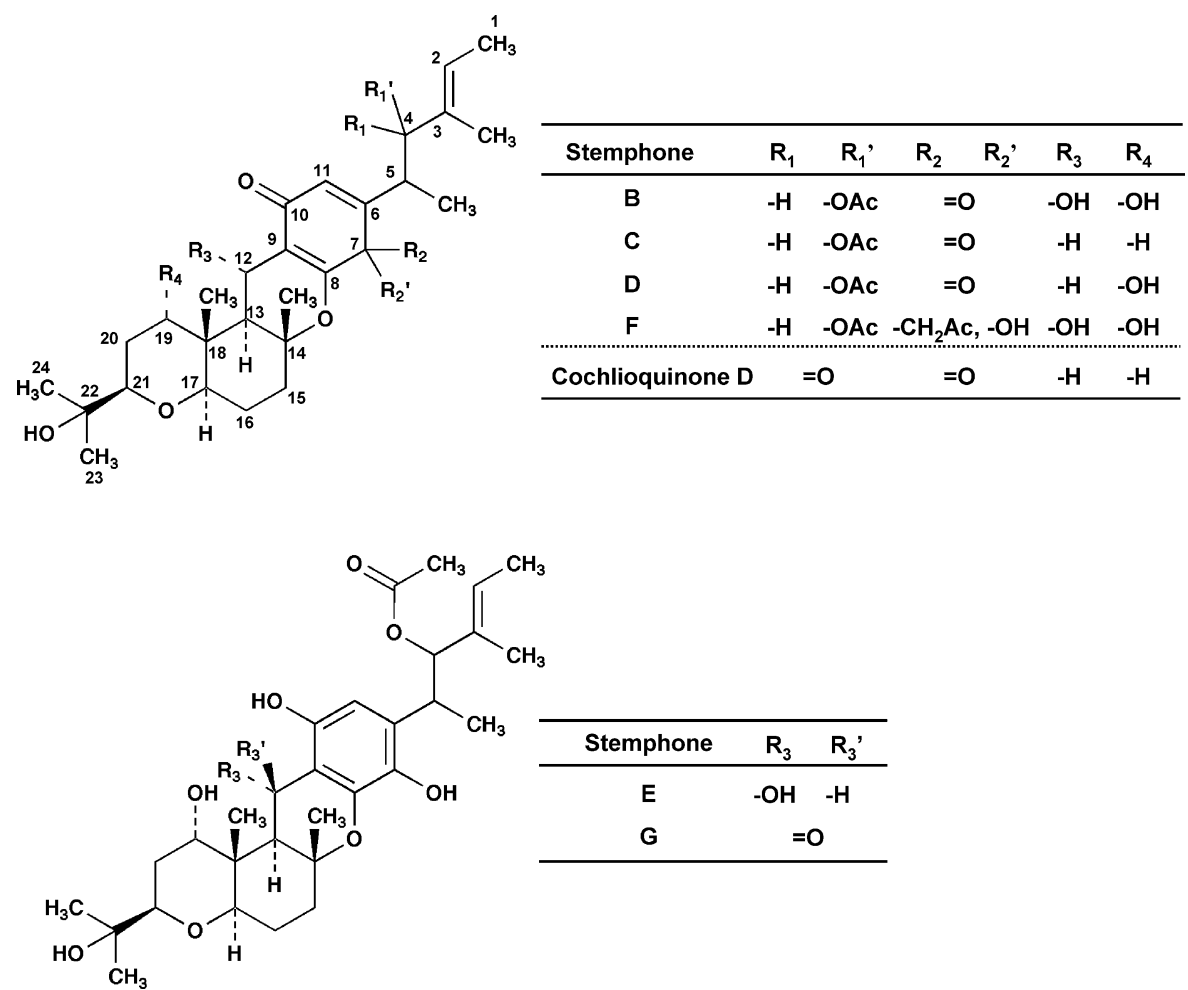

Fig. 1 Structures of stemphones B to $G$, and cochlioquinone D.

acetate extracts) were dissolved in methanol and analyzed by an HP1100 system (Hewlett Packard) under the following conditions: column, Symmetry $(2.1 \times 150 \mathrm{~mm}$, Waters); flow rate, $0.2 \mathrm{ml} / \mathrm{minute}$; mobile phase, a 20 minute linear gradient from $30 \% \mathrm{CH}_{3} \mathrm{CN}$ to $70 \% \mathrm{CH}_{3} \mathrm{CN}$ containing $0.05 \% \mathrm{H}_{3} \mathrm{PO}_{4}$ and a continuous 5-minute linear gradient from $70 \% \mathrm{CH}_{3} \mathrm{CN}$ to $100 \% \mathrm{CH}_{3} \mathrm{CN}$ containing $0.05 \% \mathrm{H}_{3} \mathrm{PO}_{4}$; detection, $\mathrm{UV}$ at $210 \mathrm{~nm}$. Stemphones D, E, $\mathrm{F}$ and $\mathrm{G}$ were eluted as peaks with retention times of 17.3, 14.5, 11.7, 18.5 minutes, respectively.

UV spectra were recorded on a spectrophotometer (DU640, Beckman). IR spectra were recorded on a Fourier transform infrared spectrometer (FT-710, Horiba). Optical rotations were measured with a digital polarimeter (DIP1000, JASCO). FAB-MS and HRFAB-MS spectra were recorded on a mass spectrometer (JMS-DX300, JEOL and JMS-AX505 HA, JEOL, respectively). The various NMR spectra were measured with a spectrometer (XL-400, Varian).

\section{Isolation of Stemphones D to $\mathbf{G}$}

Stemphones D and E were isolated from the 7-day old culture broth of the fungus. The whole broth (4.9 liters) was centrifuged at $3000 \mathrm{rpm}$ for 10 minutes to separate the mycelium and supernatant. After treating the mycelium with $\mathrm{Me}_{2} \mathrm{CO}$ (1.5 liters), the extracts were filtered and concentrated to remove $\mathrm{Me}_{2} \mathrm{CO}$. The resulting aqueous solution and the supernatant were mixed and extracted with EtOAc. The extracts were dried over $\mathrm{Na}_{2} \mathrm{SO}_{4}$ and concentrated in vacuo to dryness to yield crude materials (6.4 g). The materials were dissolved in $\mathrm{CHCl}_{3}$, applied on a silica gel column $(60 \mathrm{~g})$, and eluted stepwise with $100: 0$ (100 ml), $100: 1$ (200 ml), $50: 1$ (300 ml), $10: 1$ (300 ml), $5: 1(300 \mathrm{ml})$ and $1: 1(300 \mathrm{ml})$ of $\mathrm{CHCl}_{3}-\mathrm{CH}_{3} \mathrm{OH}$ solvents $(\mathrm{v} / \mathrm{v})$. The $50: 1$ fraction was concentrated to give a redbrown oily material $(704 \mathrm{mg})$, which was subjected to a second silica gel column $(30 \mathrm{~g})$. The material was eluted with $100: 0(50 \mathrm{ml} \times 2), 100: 1(30 \mathrm{ml} \times 5), 50: 1(25 \mathrm{ml} \times$ 10), $10: 1(30 \mathrm{ml} \times 5)$ and $5: 1(30 \mathrm{ml} \times 5)$ of $\mathrm{CHCl}_{3}-$ $\mathrm{CH}_{3} \mathrm{OH}$ solvents $(\mathrm{v} / \mathrm{v})$. The fractions of the $50: 1$ solvent were collected and concentrated in vacuo to dryness to give pure stemphone E $(318 \mathrm{mg})$ as a white powder. The $3 \mathrm{rd}$ and 4th fractions of the $10: 1$ solvent were collected and concentrated to give a yellow powder $(30 \mathrm{mg})$. This powder dissolved in $\mathrm{MeOH}(2.0 \mathrm{ml})$ was centrifuged at $3000 \mathrm{rpm}$ to remove $\mathrm{MeOH}$-insoluble impurities. The soluble supernatant $(17 \mathrm{mg})$ containing stemphone D was finally purified with preparative HPLC (column; PEGASIL ODS (Senshu Sci. Co.), $20 \times 250 \mathrm{~mm}$; solvent, $45 \% \mathrm{CH}_{3} \mathrm{CN}$; detection, $\mathrm{UV}$ at $210 \mathrm{~nm}$; flow rate, $6.0 \mathrm{ml} / \mathrm{minute})$. Under 
these conditions, stemphone $\mathrm{D}$ was eluted as a peak with a retention time of 64 minutes. The fractions were pooled and concentrated in vacuo to dryness to give pure stemphone D (1.2 mg) as a yellow powder (Fig. 3A).

Stemphones $\mathrm{F}$ and $\mathrm{G}$ were isolated from the 15-day old culture broth. The whole broth ( 0.10 liter) was centrifuged at $3000 \mathrm{rpm}$ for 10 minutes to separate the mycelium and supernatant. After treating the mycelium with $\mathrm{Me}_{2} \mathrm{CO}$, the extracts were filtered and concentrated to remove $\mathrm{Me}_{2} \mathrm{CO}$. The resulting solution and the supernatant were mixed and extracted with EtOAc. The extracts were dried over $\mathrm{Na}_{2} \mathrm{SO}_{4}$ and concentrated in vacuo to dryness to yield crude materials $(0.50 \mathrm{~g})$. The materials were dissolved in $\mathrm{CHCl}_{3}$, applied on a silica gel column (2.3 g), and eluted stepwise with $100: 0 \quad(10 \mathrm{ml} \times 4), \quad 100: 1 \quad(10 \mathrm{ml} \times 2), \quad 50: 1$ $(10 \mathrm{ml} \times 3), 10: 1(10 \mathrm{ml} \times 3), 5: 1(10 \mathrm{ml})$ and $1: 1(10 \mathrm{ml})$ of $\mathrm{CHCl}_{3}-\mathrm{CH}_{3} \mathrm{OH}$ solvents $(\mathrm{v} / \mathrm{v})$. The $2 \mathrm{nd}$ and $3 \mathrm{rd}$ fractions of the 50:1 solvent were collected and concentrated to give a yellow oil $(19.2 \mathrm{mg})$. The oil was finally purified with preparative HPLC (column; PEGASIL

\section{A) C-4 derivatives}

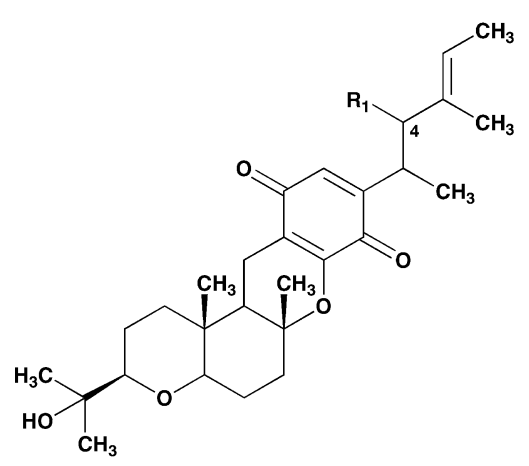

\section{B) C-11 derivatives}

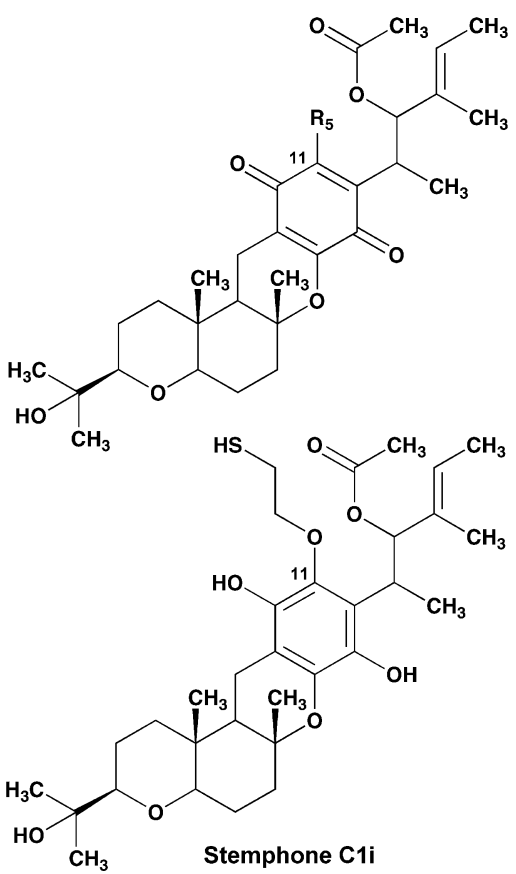

Fig. 2 Structures of stemphone derivatives.

A) C-4 derivatives, B) C-11 derivatives, C) Other derivatives.
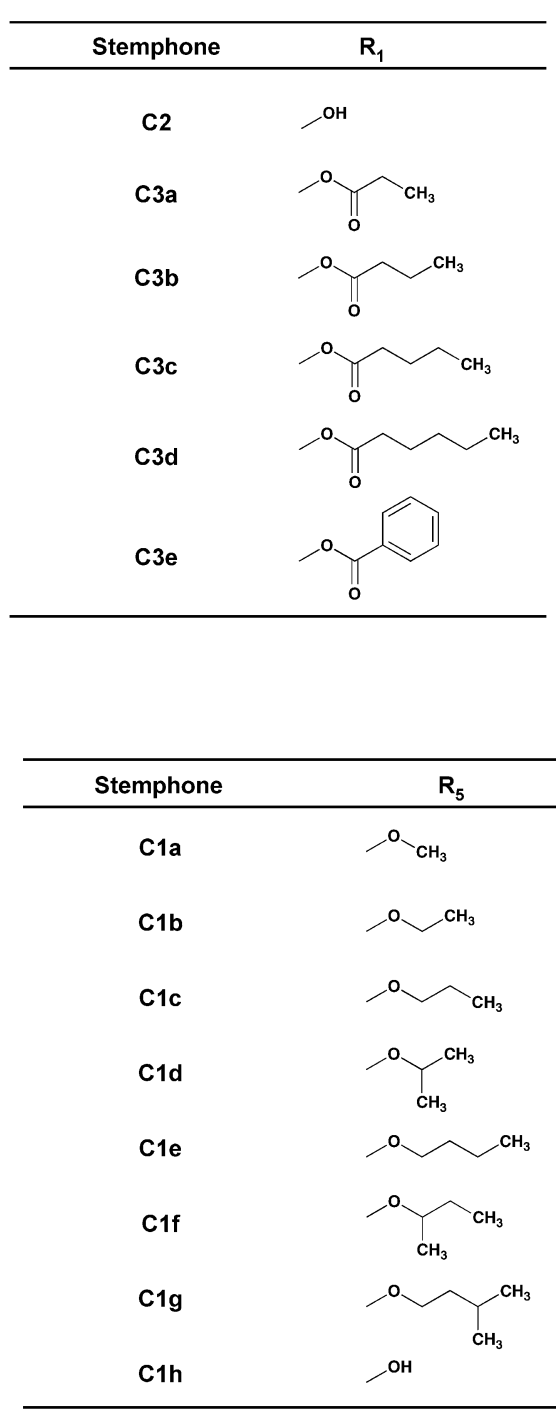


\section{C) Other derivatives}

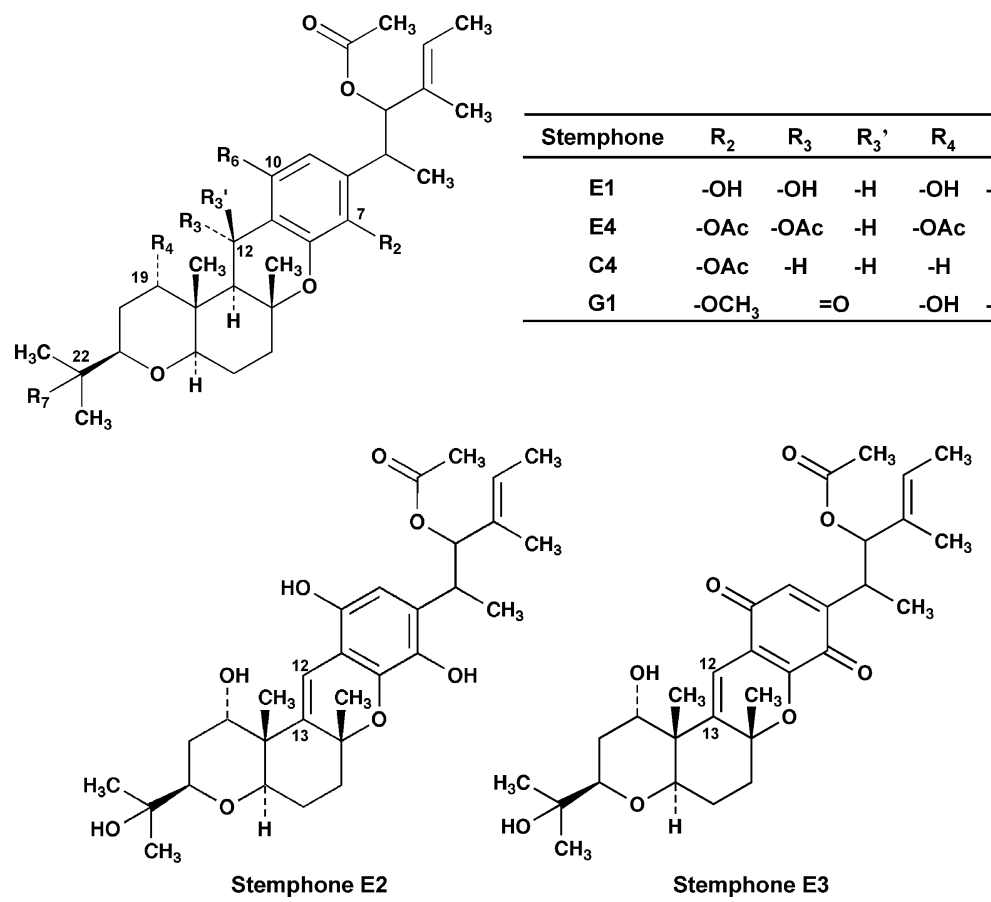

Fig. 2 (Continued)

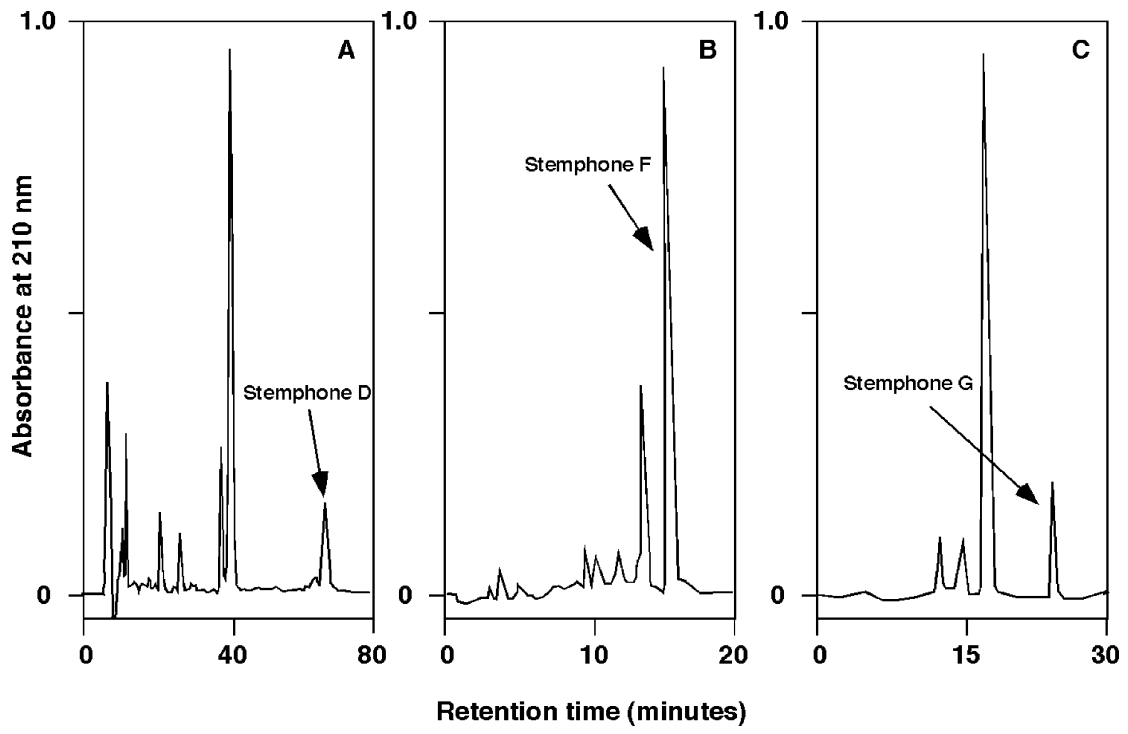

Fig. 3 Chromatographic profiles of isolation of stemphones by HPLC.

(A) Stemphone D

Column, PEGASIL ODS $20 \times 250 \mathrm{~mm}$; solvent $45 \%$ aq $\mathrm{CH}_{3} \mathrm{CN}$; detection, UV at $210 \mathrm{~nm}$; flow rate, $6.0 \mathrm{ml} / \mathrm{minute}$; sample, $2.0 \mathrm{mg}$ of active materials (obtained through second silica gel column chromatography) dissolved in $200 \mu \mathrm{l} \mathrm{MeOH}$ was injected.

(B) Stemphone F

Column, PEGASIL ODS $20 \times 250 \mathrm{~mm}$; solvent $50 \%$ aq $\mathrm{CH}_{3} \mathrm{CN}$; detection, UV at $210 \mathrm{~nm}$; flow rate, $6.0 \mathrm{ml} / \mathrm{minute}$; sample, $2.0 \mathrm{mg}$ of active materials (obtained through second silica gel column chromatography) dissolved in $200 \mu \mathrm{l} \mathrm{MeOH}$ was injected.

(C) Stemphone G

Column, PEGASIL ODS $20 \times 250 \mathrm{~mm}$; solvent $70 \%$ aq $\mathrm{CH}_{3} \mathrm{CN}$; detection, UV at $210 \mathrm{~nm}$; flow rate, $6.0 \mathrm{ml} / \mathrm{minute}$; sample, $2.0 \mathrm{mg}$ of active materials (obtained through second silica gel column chromatography) dissolved in $200 \mu \mathrm{l} \mathrm{MeOH}$ was injected. 
ODS, $20 \times 250 \mathrm{~mm}$; solvent, $50 \% \mathrm{CH}_{3} \mathrm{CN}$; detection, $\mathrm{UV}$ at $210 \mathrm{~nm}$; flow rate, $6.0 \mathrm{ml} / \mathrm{minute}$ ). Under these conditions, stemphone $\mathrm{F}$ was eluted as a peak with a retention time of 18 minutes (Fig. 3B). The fraction was concentrated in vacuo to dryness to give pure stemphone $\mathrm{F}(10.3 \mathrm{mg})$ as a yellow powder. On the other hand, the 2 nd fraction of the $100: 1$ solvent was collected and concentrated in vacuo to dryness to give a red-brown oil $(28.2 \mathrm{mg})$, which was subjected to a second silica gel column $(3.0 \mathrm{~g})$. The material was eluted with 100:0 $(1.0 \mathrm{ml} \times 40), 100: 1$ $(10 \mathrm{ml} \times 4), 1: 1(40 \mathrm{ml})$ of $\mathrm{CHCl}_{3}-\mathrm{CH}_{3} \mathrm{OH}$ solvents $(\mathrm{v} / \mathrm{v})$. The 21st to 40th fractions of the 100:0 solvent were collected and concentrated to give a red-brown oil (14.7 mg). The oil was finally purified with preparative HPLC (column; PEGASIL ODS, $20 \times 250 \mathrm{~mm}$; solvent, $70 \% \mathrm{CH}_{3} \mathrm{CN}$; detection, $\mathrm{UV}$ at $210 \mathrm{~nm}$; flow rate, $6.0 \mathrm{ml} / \mathrm{minute})$. Under these conditions, stemphone $\mathrm{G}$ was eluted as a peak with a retention time of 23.8 minutes (Fig. $3 \mathrm{C})$. The fraction was concentrated in vacuo to dryness to give pure stemphone $\mathrm{G}(1.0 \mathrm{mg})$ as a yellow powder.

\section{Preparation of C-11 Derivatives (C1a $\sim$ C1i)}

Stemphone derivatives with a diversity at C-11 (C-11 derivatives) were prepared on the basis of the basic nucleophilic reaction [4]. To a solution of stemphone $\mathrm{C}$ $(20 \mathrm{mg}, \quad 0.039 \mathrm{mmol})$ in pyridine $(400 \mu \mathrm{l}) \quad 4-$ (dimethylamino) pyridine $(5.0 \mathrm{mg}, 0.040 \mathrm{mmol})$ and methanol $(200 \mu \mathrm{l}, 7.80 \mathrm{mmol})$ were added. After the reaction mixture was stirred at $60^{\circ} \mathrm{C}$ for 48 hours, EtOAc and distilled water were added. The organic layer was recovered, dried over anhydrous $\mathrm{Na}_{2} \mathrm{SO}_{4}$, filtered and concentrated to dryness to afford a yellow material. This material was purified by HPLC (column; PEGASIL ODS, $20 \times 250 \mathrm{~mm}$; solvent, $80 \% \mathrm{CH}_{3} \mathrm{CN}$; detection, $\mathrm{UV}$ at $210 \mathrm{~nm}$; flow rate, $6.0 \mathrm{ml} /$ minute) to give 11 -methoxy stemphone $\mathrm{C}(\mathrm{C} 1 \mathrm{a}, 40.4 \%)$ and 11-hydroxy stemphone $\mathrm{C}$ as yellow oils. Moreover, the other derivatives were obtained using the following alcohols; ethanol $(\mathrm{C} 1 \mathrm{~b}$, 35.6\%), 1-propanol (C1c, 29.9\%), 2-propanol (C1d, 17.7\%), 1-butanol (C1e, 17.5\%), 2-butanol (C1f, 2.11\%), 3-methyl-1-butanol (C1g, 24.9\%) and 2-mercaptoethanol (C1i, 53.0\%).

11-Methoxy stemphone C (C1a): ${ }^{1} \mathrm{H}-\mathrm{NMR}(300 \mathrm{MHz}$, $\left.\mathrm{CDCl}_{3}\right) \delta 0.88(\mathrm{~s}, 3 \mathrm{H}), 1.02(\mathrm{~d}, 3 \mathrm{H}, J=8.0 \mathrm{~Hz}), 1.16(\mathrm{~s}$, $3 \mathrm{H}), 1.18(\mathrm{~s}, 3 \mathrm{H}), 1.20,1.86(\mathrm{~m}, 2 \mathrm{H}), 1.28(\mathrm{~s}, 3 \mathrm{H}), 1.41$ $(\mathrm{dd}, 1 \mathrm{H}, J=13.0,5.0 \mathrm{~Hz}), 1.48,1.66(\mathrm{~m}, 2 \mathrm{H}), 1.57,1.76$ $(\mathrm{m}, 2 \mathrm{H}), 1.62(\mathrm{~s}, 3 \mathrm{H}), 1.63(\mathrm{~d}, 3 \mathrm{H}, J=7.0 \mathrm{~Hz}), 1.80,2.18$ (m, 2H), 1.87 (s, 3H), 2.18, 2.48 (dd, 2H, J=19.0, $13.0 \mathrm{~Hz}$, $J=18.0,5.0 \mathrm{~Hz}$ ), 3.10 (dd, $1 \mathrm{H}, J=12.0,4.0 \mathrm{~Hz}), 3.21$ (dd, $1 \mathrm{H}, J=12.0,3.0 \mathrm{~Hz}), 3.49(\mathrm{dq}, 1 \mathrm{H}, J=9.0,8.0 \mathrm{~Hz}), 4.03$ (s, $3 \mathrm{H}), 5.44(\mathrm{~d}, 1 \mathrm{H}, J=9.0 \mathrm{~Hz}), 5.68(\mathrm{q}, 1 \mathrm{H}, J=7.0 \mathrm{~Hz}) ;{ }^{13} \mathrm{C}-$
NMR $\left(75 \mathrm{MHz}, \mathrm{CDCl}_{3}\right) \delta 10.6,12.2,13.2,15.0,16.3,20.8$, $21.2,21.3,23.8,25.2,26.1,31.5,35.5,36.8,37.0,46.7$, $61.5,71.8,80.6,81.7,84.0,84.8,115.9,126.2,130.5$, 132.4, 152.1, 156.6, 169.9, 181.1, 183.0; HR FAB-MS ( $m / z$ ) found: 544.3016, calcd: $544.3036\left(\mathrm{M}^{+}\right)$for $\mathrm{C}_{31} \mathrm{H}_{44} \mathrm{O}_{8}$.

11-Ethoxy stemphone $\mathrm{C}(\mathrm{C} 1 \mathrm{~b})$ : ${ }^{1} \mathrm{H}-\mathrm{NMR}(300 \mathrm{MHz}$, $\left.\mathrm{CDCl}_{3}\right) \delta 0.88(\mathrm{~s}, 3 \mathrm{H}), 1.03(\mathrm{~d}, 3 \mathrm{H}, J=7.5 \mathrm{~Hz}), 1.16(\mathrm{~s}$, $3 \mathrm{H}), 1.18(\mathrm{~s}, 3 \mathrm{H}), 1.18,1.88(\mathrm{~m}, 2 \mathrm{H}), 1.27(\mathrm{~s}, 3 \mathrm{H}), 1.42$ (dd, $1 \mathrm{H}, J=13.0,5.0 \mathrm{~Hz}), 1.43(\mathrm{t}, 3 \mathrm{H}, J=7.5 \mathrm{~Hz}), 1.48$, $1.66(\mathrm{~m}, 2 \mathrm{H}), 1.60,1.78(\mathrm{~m}, 2 \mathrm{H}), 1.62(\mathrm{~s}, 3 \mathrm{H}), 1.63(\mathrm{~d}, 3 \mathrm{H}$, $J=8.0 \mathrm{~Hz}), 1.86(\mathrm{~s}, 3 \mathrm{H}), 1.90,2.17(\mathrm{~m}, 2 \mathrm{H}), 2.14,2.52(\mathrm{dd}$, $2 \mathrm{H}, J=19.0,13.0 \mathrm{~Hz}, J=18.0,5.0 \mathrm{~Hz}), 3.11(\mathrm{dd}, 1 \mathrm{H}$, $J=12.0,4.0 \mathrm{~Hz}), 3.21(\mathrm{dd}, 1 \mathrm{H}, J=12.0,3.0 \mathrm{~Hz}), 3.45$ (dq, $1 \mathrm{H}, J=10.0,8.0 \mathrm{~Hz}$ ), 4.33 (q, 1H, $J=7.5 \mathrm{~Hz}), 5.48$ (d, 1H, $J=10.0 \mathrm{~Hz}), 5.65(\mathrm{q}, 1 \mathrm{H}, J=8.0 \mathrm{~Hz}) ;{ }^{13} \mathrm{C}-\mathrm{NMR}(75 \mathrm{MHz}$, $\left.\mathrm{CDCl}_{3}\right) \delta 10.9,12.4,13.4,15.2,16.1,16.5,21.0,21.6$, $21.7,24.0,25.4,26.3,31.8,35.8,37.0,37.3,46.9,70.3$, $72.1,80.8,81.9,84.3,85.1,116.0,126.3,132.7,133.0$, 152.4, 156.5, 170.1, 182.4, 183.4; HR FAB-MS $(\mathrm{m} / \mathrm{z})$ found: 581.3097, calcd: $581.3090 \quad(\mathrm{M}+\mathrm{Na})^{+}$for $\mathrm{C}_{32} \mathrm{H}_{46} \mathrm{O}_{8} \mathrm{Na}$.

11-(n-Propanoxy) stemphone C (C1c): ${ }^{1} \mathrm{H}-\mathrm{NMR}$ $\left(300 \mathrm{MHz}, \mathrm{CDCl}_{3}\right) \delta 0.88(\mathrm{~s}, 3 \mathrm{H}), 1.03(\mathrm{~d}, 3 \mathrm{H}, J=8.0 \mathrm{~Hz})$, $1.04(\mathrm{t}, 3 \mathrm{H}, J=8.0 \mathrm{~Hz}), 1.16(\mathrm{~s}, 3 \mathrm{H}), 1.18(\mathrm{~s}, 3 \mathrm{H}), 1.18$, $1.87(\mathrm{~m}, 2 \mathrm{H}), 1.27(\mathrm{~s}, 3 \mathrm{H}), 1.42(\mathrm{dd}, 1 \mathrm{H}, J=13.0,5.0 \mathrm{~Hz})$, $1.46,1.66(\mathrm{~m}, 2 \mathrm{H}), 1.60,1.78(\mathrm{~m}, 2 \mathrm{H}), 1.62(\mathrm{~s}, 3 \mathrm{H}), 1.63$ $(\mathrm{d}, 3 \mathrm{H}, J=8.0 \mathrm{~Hz}), 1.84(\mathrm{~m}, 2 \mathrm{H}), 1.86(\mathrm{~s}, 3 \mathrm{H}), 1.88,2.17$ (m, 2H), 2.04, 2.48 (dd, 2H, $J=18.0,13.0 \mathrm{~Hz}, J=18.0$, $5.0 \mathrm{~Hz}), 3.10(\mathrm{dd}, 1 \mathrm{H}, J=12.0,4.0 \mathrm{~Hz}), 3.20(\mathrm{dd}, 1 \mathrm{H}$, $J=12.0,3.0 \mathrm{~Hz}), 3.47(\mathrm{dq}, 1 \mathrm{H}, J=10.0,8.0 \mathrm{~Hz}), 4.24(\mathrm{~m}$, $2 \mathrm{H}), 5.49$ (d, $1 \mathrm{H}, J=10.0 \mathrm{~Hz}), 5.64(\mathrm{q}, 1 \mathrm{H}, J=7.5 \mathrm{~Hz}) ;{ }^{13} \mathrm{C}-$ NMR $\left(75 \mathrm{MHz}, \mathrm{CDCl}_{3}\right) \delta 10.6,10.8,12.4,13.4,15.3,16.5$, 21.0, 21.1, 21.6, 23.9, 24.0, 25.4, 26.3, 31.8, 35.8, 37.0, $37.3,46.9,72.1,76.0,80.8,84.3,85.1,116.0,126.4,130.2$, 132.7, 152.4, 156.6, 170.1, 182.4, 183.4; HR FAB-MS $(\mathrm{m} / \mathrm{z})$ found: 595.3250, calcd: $595.3247(\mathrm{M}+\mathrm{Na})^{+}$for $\mathrm{C}_{33} \mathrm{H}_{48} \mathrm{O}_{8} \mathrm{Na}$.

11-(1-Methyl-ethoxy) stemphone $\mathrm{C}(\mathrm{C} 1 \mathrm{~d}):{ }^{1} \mathrm{H}-\mathrm{NMR}$ $\left(300 \mathrm{MHz}, \mathrm{CDCl}_{3}\right) \delta 0.88(\mathrm{~s}, 3 \mathrm{H}), 1.04(\mathrm{~d}, 3 \mathrm{H}, J=7.0 \mathrm{~Hz})$, $1.16(\mathrm{~s}, 3 \mathrm{H}), 1.18(\mathrm{~s}, 3 \mathrm{H}), 1.18,1.87(\mathrm{~m}, 2 \mathrm{H}), 1.28(\mathrm{~s}, 3 \mathrm{H})$, $1.35(\mathrm{~d}, 3 \mathrm{H}, J=7.0 \mathrm{~Hz}), 1.37$ (d, 3H, $J=7.0 \mathrm{~Hz}), 1.42$ (dd, $1 \mathrm{H}, J=13.0,5.0 \mathrm{~Hz}), 1.48,1.68(\mathrm{~m}, 2 \mathrm{H}), 1.61$ (s, 3H), 1.60, $1.78(\mathrm{~m}, 2 \mathrm{H}), 1.63(\mathrm{~d}, 3 \mathrm{H}, J=7.5 \mathrm{~Hz}), 1.85(\mathrm{~s}, 3 \mathrm{H}), 1.88$, $2.17(\mathrm{~m}, 2 \mathrm{H}), 2.04,2.48(\mathrm{dd}, 2 \mathrm{H}, J=18.0,13.0 \mathrm{~Hz}, J=18.0$, $5.0 \mathrm{~Hz}), 2.18(\mathrm{~m}, 1 \mathrm{H}), 3.11(\mathrm{dd}, 1 \mathrm{H}, J=12.0,4.0 \mathrm{~Hz}), 3.21$ $(\mathrm{dd}, 1 \mathrm{H}, J=12.0,3.0 \mathrm{~Hz}), 3.46(\mathrm{dq}, 1 \mathrm{H}, J=10.0,7.0 \mathrm{~Hz})$, $5.52(\mathrm{~d}, 1 \mathrm{H}, J=10.0 \mathrm{~Hz}), 5.66(\mathrm{q}, 1 \mathrm{H}, J=8.0 \mathrm{~Hz}) ;{ }^{13} \mathrm{C}-\mathrm{NMR}$ $\left(75 \mathrm{MHz}, \mathrm{CDCl}_{3}\right) \delta 10.8,12.4,13.4,15.6,16.5,20.9,21.4$, 21.6, 23.4, 24.0, 25.4, 26.3, 32.3, 35.8, 37.0, 37.3, 46.9, $72.1,80.8,82.1,84.3,85.1,115.8,126.3,132.6,132.7$, $152.5,155.6,169.9,182.4,183.6$; HR FAB-MS $(\mathrm{m} / \mathrm{z})$ 
found: 572.3348, calcd: $572.3249\left(\mathrm{M}^{+}\right)$for $\mathrm{C}_{33} \mathrm{H}_{48} \mathrm{O}_{8}$.

11-(n-Butoxy) stemphone C (C1e): ${ }^{1} \mathrm{H}-\mathrm{NMR}(300 \mathrm{MHz}$, $\left.\mathrm{CDCl}_{3}\right) \delta 0.88(\mathrm{~s}, 3 \mathrm{H}), 0.98(\mathrm{~d}, 6 \mathrm{H}, J=7.0 \mathrm{~Hz}), 1.03(\mathrm{~d}, 3 \mathrm{H}$, $J=7.5 \mathrm{~Hz}), 1.16(\mathrm{~s}, 3 \mathrm{H}), 1.18(\mathrm{~s}, 3 \mathrm{H}), 1.18,1.86(\mathrm{~m}, 2 \mathrm{H})$, $1.27(\mathrm{~s}, 3 \mathrm{H}), 1.42(\mathrm{dd}, 1 \mathrm{H}, J=13.0,5.0 \mathrm{~Hz}), 1.48,1.64(\mathrm{~m}$, $2 \mathrm{H}), 1.51(\mathrm{~m}, 2 \mathrm{H}), 1.58,1.78(\mathrm{~m}, 2 \mathrm{H}), 1.62(\mathrm{~s}, 3 \mathrm{H}), 1.63(\mathrm{~d}$, $3 \mathrm{H}, J=8.0 \mathrm{~Hz}), 1.76(\mathrm{~m}, 2 \mathrm{H}), 1.85(\mathrm{~s}, 3 \mathrm{H}), 1.87,2.18(\mathrm{~m}$, $2 \mathrm{H}), 2.04,2.48(\mathrm{dd}, 2 \mathrm{H}, J=18.0,13.0 \mathrm{~Hz}, J=18.0,5.0 \mathrm{~Hz})$, $3.10(\mathrm{dd}, 1 \mathrm{H}, J=12.0,4.0 \mathrm{~Hz}), 3.20(\mathrm{dd}, 1 \mathrm{H}, J=12.0$, $3.0 \mathrm{~Hz}), 3.46(\mathrm{dq}, 1 \mathrm{H}, J=10.0,8.0 \mathrm{~Hz}), 4.28(\mathrm{~m}, 2 \mathrm{H}), 5.48$ $(\mathrm{d}, 1 \mathrm{H}, J=10.0 \mathrm{~Hz}), 5.64(\mathrm{q}, 1 \mathrm{H}, J=8.0 \mathrm{~Hz}) ;{ }^{13} \mathrm{C}-\mathrm{NMR}$ $\left(75 \mathrm{MHz}, \mathrm{CDCl}_{3}\right) \delta 10.8,12.4,13.4,14.1,15.3,16.5,19.3$, 21.0, 21.4, 21.6, 24.0, 25.4, 26.3, 31.8, 32.6, 35.7, 37.0, $37.3,46.9,72.1,74.2,80.8,82.0,84.3,85.1,115.9,126.3$, 130.4, 132.7, 152.4, 156.6, 170.1, 182.4, 183.4; HR FABMS $(\mathrm{m} / \mathrm{z})$ found: 609.3417 , calcd: $609.3403(\mathrm{M}+\mathrm{Na})^{+}$for $\mathrm{C}_{34} \mathrm{H}_{50} \mathrm{O}_{8} \mathrm{Na}$.

(1-Methyl-n-propanoxy) stemphone C (C1f): ${ }^{1} \mathrm{H}-\mathrm{NMR}$ $\left(300 \mathrm{MHz}, \mathrm{CDCl}_{3}\right) \delta 0.88(\mathrm{~s}, 3 \mathrm{H}), 1.00(\mathrm{t}, 3 \mathrm{H}, J=7.0 \mathrm{~Hz})$, $1.03(\mathrm{~d}, 3 \mathrm{H}, J=8.0 \mathrm{~Hz}), 1.16(\mathrm{~s}, 3 \mathrm{H}), 1.18(\mathrm{~s}, 3 \mathrm{H}), 1.20$, $1.90(\mathrm{~m}, 2 \mathrm{H}), 1.27(\mathrm{~s}, 3 \mathrm{H}), 1.28(\mathrm{~d}, 3 \mathrm{H}, J=5.0 \mathrm{~Hz}), 1.43$ $(\mathrm{m}, 1 \mathrm{H}), 1.48,1.64(\mathrm{~m}, 2 \mathrm{H}), 1.53,1.78(\mathrm{~m}, 2 \mathrm{H}), 1.60(\mathrm{~s}$, $3 \mathrm{H}), 1.63(\mathrm{~d}, 3 \mathrm{H}, J=7.0 \mathrm{~Hz}), 1.64,1.78(\mathrm{~m}, 2 \mathrm{H}), 1.82, .18$ $(\mathrm{m}, 2 \mathrm{H}), 1.84(\mathrm{~s}, 3 \mathrm{H}), 2.05,2.50(\mathrm{~m}, 2 \mathrm{H}), 2.52(\mathrm{~m}, 1 \mathrm{H})$, $3.10(\mathrm{dd}, 1 \mathrm{H}, J=12.0,4.0 \mathrm{~Hz}), 3.21(\mathrm{dd}, 1 \mathrm{H}, J=12.0$, $3.0 \mathrm{~Hz}), 3.46(\mathrm{dq}, 1 \mathrm{H}, J=11.0,7.0 \mathrm{~Hz}), 5.52(\mathrm{~d}, 1 \mathrm{H}$, $J=10.0 \mathrm{~Hz}$ ), 5.65 (q, $1 \mathrm{H}, J=7.0 \mathrm{~Hz}) ;{ }^{13} \mathrm{C}-\mathrm{NMR}(75 \mathrm{MHz}$, $\left.\mathrm{CDCl}_{3}\right) \delta 10.0,10.8,12.4,13.4,15.5,16.5,20.5,20.9$, $21.4,21.6,24.0,25.4,26.3,30.4,32.3,35.8,37.0,37.3$, 46.9, 72.1, 80.7, 81.2, 82.1, 84.3, 85.1, 115.7, 126.3, 130.9, $132.7,152.5,155.7,169.9,182.3,183.6$; HR FAB-MS ( $m / z$ ) found: 586.3487, calcd: $586.3506\left(\mathrm{M}^{+}\right)$for $\mathrm{C}_{34} \mathrm{H}_{50} \mathrm{O}_{8}$.

11-(3-Methyl-1-butoxy) stemphone $\mathrm{C}(\mathrm{C} 1 \mathrm{~g}):{ }^{1} \mathrm{H}-\mathrm{NMR}$ $\left(300 \mathrm{MHz}, \mathrm{CDCl}_{3}\right) \delta 0.88(\mathrm{~s}, 3 \mathrm{H}), 0.97(\mathrm{~d}, 6 \mathrm{H}, J=7.0 \mathrm{~Hz})$, 1.03 (d, 3H, J=7 Hz), 1.16 (s, 3H), 1.18 (s, 3H), 1.21, 1.86 $(\mathrm{m}, 2 \mathrm{H}), 1.27(\mathrm{~s}, 3 \mathrm{H}), 1.42(\mathrm{dd}, 1 \mathrm{H}, J=13.0,5.0 \mathrm{~Hz}), 1.48$, $1.64(\mathrm{~m}, 2 \mathrm{H}), 1.58,1.78(\mathrm{~m}, 2 \mathrm{H}), 1.62(\mathrm{~s}, 3 \mathrm{H}), 1.63(\mathrm{~d}, 3 \mathrm{H}$, $J=7.0 \mathrm{~Hz}), 1.68(\mathrm{~m}, 2 \mathrm{H}), 1.79,2.18(\mathrm{~m}, 2 \mathrm{H}), 1.82(\mathrm{~m}, 1 \mathrm{H})$, 1.86 (s, 3H), 2.08, 2.48 (dd, 2H, $J=18.0,13.0 \mathrm{~Hz}, J=18.0$, $5.0 \mathrm{~Hz}), 3.10(\mathrm{dd}, 1 \mathrm{H}, J=12.0,4.0 \mathrm{~Hz}), 3.20(\mathrm{dd}, 1 \mathrm{H}$, $J=12.0,3.0 \mathrm{~Hz}), 3.45$ (dq, $1 \mathrm{H}, J=10.0,7.0 \mathrm{~Hz}), 4.30(\mathrm{~m}$, $2 \mathrm{H}), 5.48$ (d, 1H, $J=10.0 \mathrm{~Hz}), 5.64$ (q, $1 \mathrm{H}, J=7.0 \mathrm{~Hz}) ;{ }^{13} \mathrm{C}-$ NMR $\left(75 \mathrm{MHz}, \mathrm{CDCl}_{3}\right) \delta 10.8,12.4,13.4,15.3,16.5,21.0$, 21.5, 21.6, 22.8, 24.0, 25.1, 25.4, 26.3, 33.9, 35.8, 37.0, $37.3,39.3,46.9,72.1,73.0,80.8,82.0,84.3,85.1,116.0$, 126.4, 130.3, 132.7, 152.4, 156.6, 170.1, 182.4, 183.4; HR FAB-MS $(\mathrm{m} / \mathrm{z})$ found: 600.3675 , calcd: $600.3662\left(\mathrm{M}^{+}\right)$for $\mathrm{C}_{35} \mathrm{H}_{52} \mathrm{O}_{8}$.

11-Hydroxy stemphone C (C1h): ${ }^{1} \mathrm{H}-\mathrm{NMR}(300 \mathrm{MHz}$, $\left.\mathrm{CDCl}_{3}\right) \delta 0.89(\mathrm{~s}, 3 \mathrm{H}), 1.04(\mathrm{~d}, 3 \mathrm{H}, J=7.0 \mathrm{~Hz}), 1.16(\mathrm{~s}$, $3 \mathrm{H}), 1.18(\mathrm{~s}, 3 \mathrm{H}), 1.18,1.87(\mathrm{~m}, 2 \mathrm{H}), 1.30(\mathrm{~s}, 3 \mathrm{H}), 1.42$ (dd, 1H, $J=13.0,5.0 \mathrm{~Hz}), 1.48,1.68(\mathrm{~m}, 2 \mathrm{H}), 1.58,1.78$ $(\mathrm{m}, 2 \mathrm{H}), 1.62(\mathrm{~s}, 3 \mathrm{H}), 1.63(\mathrm{~d}, 3 \mathrm{H}, J=8.0 \mathrm{~Hz}), 1.86(\mathrm{~s}, 3 \mathrm{H})$, 1.87, $2.20(\mathrm{~m}, 2 \mathrm{H}), 2.20,2.52(\mathrm{dd}, 2 \mathrm{H}, J=18.0,13.0 \mathrm{~Hz}$, $J=18.0,5.0 \mathrm{~Hz}$ ), $3.10(\mathrm{dd}, 1 \mathrm{H}, J=12.0,4.0 \mathrm{~Hz}), 3.21$ (dd, $1 \mathrm{H}, J=12.0,3.0 \mathrm{~Hz}), 3.39(\mathrm{dq}, 1 \mathrm{H}, J=11.0,7.0 \mathrm{~Hz}), 5.52$ $(\mathrm{d}, 1 \mathrm{H}, J=11.0 \mathrm{~Hz}), 5.66(\mathrm{q}, 1 \mathrm{H}, J=8.0 \mathrm{~Hz}) ;{ }^{13} \mathrm{C}-\mathrm{NMR}$ $\left(75 \mathrm{MHz}, \mathrm{CDCl}_{3}\right) \delta 10.9,12.5,13.4,14.7,16.3,21.1,21.5$, 21.6, 24.0, 25.4, 26.3, 31.5, 35.8, 37.0, 37.3, 46.8, 72.1, $81.4,81.9,84.2,85.1,113.3,118.8,126.3,132.6,151.8$, 154.7, 170.3, 181.5, 182.4; HR FAB-MS $(\mathrm{m} / \mathrm{z})$ found: 553.2782, calcd: $553.2777(\mathrm{M}+\mathrm{Na})^{+}$for $\mathrm{C}_{30} \mathrm{H}_{42} \mathrm{O}_{8} \mathrm{Na}$.

11-(2-Mercapto-ethoxy) stemphone C (C1i): ${ }^{1} \mathrm{H}-\mathrm{NMR}$ $\left(300 \mathrm{MHz}, \mathrm{CDCl}_{3}\right) \delta 0.91(\mathrm{~s}, 3 \mathrm{H}), 1.07$ (d, 3H, $\left.J=7.5 \mathrm{~Hz}\right)$, 1.17 (s, 3H), $1.18(\mathrm{~s}, 3 \mathrm{H}), 1.22,1.98(\mathrm{~m}, 2 \mathrm{H}), 1.23(\mathrm{~s}, 3 \mathrm{H})$, $1.52(\mathrm{dd}, 1 \mathrm{H}, J=13.0,5.0 \mathrm{~Hz}), 1.62,1.78(\mathrm{~m}, 2 \mathrm{H}), 1.64(\mathrm{~s}$, $3 \mathrm{H}), 1.66(\mathrm{~d}, 3 \mathrm{H}, J=7.0 \mathrm{~Hz}), 1.69(\mathrm{~s}, 3 \mathrm{H}), 1.98,2.04(\mathrm{~m}$, 2H), 2.40, $2.72(\mathrm{dd}, 2 \mathrm{H}, J=19.0,13.0 \mathrm{~Hz}, J=18.0,5.0 \mathrm{~Hz})$, 2.82, $2.94(\mathrm{~m}, 2 \mathrm{H}), 3.14(\mathrm{dd}, 1 \mathrm{H}, J=12.0,4.0 \mathrm{~Hz}), 3.24(\mathrm{dd}$, $1 \mathrm{H}, J=12.0,3.0 \mathrm{~Hz}), 4.07$ (dq, 1H, $J=10.0,7.5 \mathrm{~Hz}), 5.98$ (d, $1 \mathrm{H}, J=10.0 \mathrm{~Hz}), 5.74$ (q, $1 \mathrm{H}, J=8.0 \mathrm{~Hz}) ;{ }^{13} \mathrm{C}-\mathrm{NMR}$ $\left(75 \mathrm{MHz}, \mathrm{CDCl}_{3}\right) \delta 11.1,12.3,13.5,15.4,18.2,21.2,21.3$, 21.6, 24.0, 25.5, 26.3, 35.7, 37.0, 37.9, 38.5, 39.0, 47.5, $47.5,60.6,72.2,78.3,81.7,84.5,85.1,107.5,107.6,126.1$, 129.4, 133.1, 138.0, 142.7, 149.4, 169.9; HR FAB-MS $(\mathrm{m} / \mathrm{z})$ found: 592.3089, calcd: $592.3070\left(\mathrm{M}^{+}\right)$for $\mathrm{C}_{32} \mathrm{H}_{46} \mathrm{O}_{8} \mathrm{~S}$.

\section{Preparation of Deacetyl Stemphone C (C2)}

Stemphone C $(100 \mathrm{mg}, 0.211 \mathrm{mmol})$ was reacted with lithium aluminium hydride $(100 \mathrm{mg}, 2.63 \mathrm{mmol})$ in diethylether $(4.0 \mathrm{ml})$ at $0^{\circ} \mathrm{C}$. After 15 minutes, the reaction was quenched with EtOAc and then washed with $1.0 \mathrm{~N}$ $\mathrm{HCl}$. The organic layer was recovered, dried over anhydrous $\mathrm{Na}_{2} \mathrm{SO}_{4}$, filtered and concentrated in vacuo to dryness. The residue was purified by preparative HPLC (column; PEGASIL ODS, $20 \times 250 \mathrm{~mm}$; solvent, $80 \% \quad \mathrm{CH}_{3} \mathrm{CN}$; detection, $\mathrm{UV}$ at $210 \mathrm{~nm}$; flow rate, $6.0 \mathrm{ml} / \mathrm{minute})$ to afford 4-deacetyl stemphone C (C2, $42.1 \mathrm{mg}, 42.2 \%)$.

4-Deacetyl stemphone C (C2): ${ }^{1} \mathrm{H}-\mathrm{NMR}(300 \mathrm{MHz}$, $\left.\mathrm{CDCl}_{3}\right) \delta 0.88(\mathrm{~s}, 3 \mathrm{H}), 0.99(\mathrm{~d}, 3 \mathrm{H}, J=6.0 \mathrm{~Hz}), 1.16(\mathrm{~s}$, $3 \mathrm{H}), 1.17(\mathrm{~s}, 3 \mathrm{H}), 1.21,1.88(\mathrm{~m}, 2 \mathrm{H}), 1.27(\mathrm{~s}, 3 \mathrm{H}), 1.43$ (dd, 1H, $J=13.0,5.0 \mathrm{~Hz}), 1.47,1.64$ (m, 2H), 1.56, 1.77 $(\mathrm{m}, 2 \mathrm{H}), 1.61(\mathrm{~d}, 3 \mathrm{H}, J=8.0 \mathrm{~Hz}), 1.63(\mathrm{~s}, 3 \mathrm{H}), 1.78,2.16$ (m, 2H), 2.12, 2.52 (dd, 2H, $J=19.0,13.0 \mathrm{~Hz}, J=19.0$, $5.0 \mathrm{~Hz}), 3.14(\mathrm{dd}, 1 \mathrm{H}, J=13.0,4.0 \mathrm{~Hz}), 3.21(\mathrm{dd}, 1 \mathrm{H}$, $J=12.0,3.0 \mathrm{~Hz}), 3.12(\mathrm{~m}, 1 \mathrm{H}), 3.90(\mathrm{~d}, 1 \mathrm{H}, J=10.0 \mathrm{~Hz})$, $5.48(\mathrm{q}, 1 \mathrm{H}, J=7.0 \mathrm{~Hz}), 6.52(\mathrm{~s}, 1 \mathrm{H}) ;{ }^{13} \mathrm{C}-\mathrm{NMR}(75 \mathrm{MHz}$, $\left.\mathrm{CDCl}_{3}\right) \delta 10.9,12.4,13.3,16.6,16.9,21.0,21.6,24.0$, 25.4, 26.3, 35.8, 37.0, 37.4, 46.8, 72.1, 80.7, 82.6, 84.3, $85.1,118.1,123.7,132.7,136.4,149.4,152.5,182.8$, 187.5; HR FAB-MS $(\mathrm{m} / \mathrm{z})$ found: $473.2896(\mathrm{M}+\mathrm{H})^{+}$, 
calcd: $473.2903(\mathrm{M}+\mathrm{H})^{+}$for $\mathrm{C}_{28} \mathrm{H}_{40} \mathrm{O}_{6}$.

\section{Preparation of C-4 Derivatives from Deacetyl Stemphone C (C3a $\sim$ C3e)}

To a solution of deacetyl stemphone C (5.0 mg, $0.011 \mathrm{mmol})$ in $\mathrm{CH}_{2} \mathrm{Cl}_{2}(500 \mu \mathrm{l})$ propionic anhydride (15 $\mu \mathrm{l}, 0.11 \mathrm{mmol})$, triethylamine $(15 \mu \mathrm{l}, 0.11 \mathrm{mmol})$ and $4-$ (dimethylamino) pyridine $(1.0 \mathrm{mg}, 0.0080 \mathrm{mmol})$ were added, and the resulting solution was stirred at room temperature. After 10 hours, the reaction mixture was diluted with $1.0 \mathrm{~N} \mathrm{HCl}$ and the aqueous phase was extracted with EtOAc. The organic layer was recovered, dried over anhydrous $\mathrm{Na}_{2} \mathrm{SO}_{4}$, filtered and concentrated in vacuo to dryness. The product was purified by preparative HPLC (column; PEGASIL ODS, $20 \times 250 \mathrm{~mm}$; solvent, $80 \% \mathrm{CH}_{3} \mathrm{CN}$; detection, $\mathrm{UV}$ at $210 \mathrm{~nm}$; flow rate, $6.0 \mathrm{ml} / \mathrm{minute})$ to give 4-deacetyl-4- $O$-propionyl stemphone $\mathrm{C}(\mathrm{C} 3 \mathrm{a}, 2.57 \mathrm{mg}, 44.9 \%)$ as a yellow powder. Moreover, other C-4 derivatives were obtained using the following acid anhydrides instead of propionic anhydride; $n$-butyric anhydride (C3b, 41.3\%), n-valeric anhydride (C3c, 46.6\%), $n$-hexanoic anhydride (C3d, 22.4\%) and benzoic anhydride (C3e, 37.7\%).

4-Deacetyl-4-O-propionyl stemphone C (C3a): ${ }^{1} \mathrm{H}-\mathrm{NMR}$ $\left(300 \mathrm{MHz}, \mathrm{CDCl}_{3}\right) \delta 0.89(\mathrm{~s}, 3 \mathrm{H}), 1.03(\mathrm{t}, 3 \mathrm{H}, J=8.0 \mathrm{~Hz})$, 1.03 (d, 3H, J=7 Hz), 1.17 (s, 3H), 1.18 (s, 3H), 1.18, 1.84 (m, $2 \mathrm{H}), 1.28(\mathrm{~s}, 3 \mathrm{H}), 1.42(\mathrm{dd}, 1 \mathrm{H}, J=13.0,5.0 \mathrm{~Hz}), 1.42$, $1.63(\mathrm{~m}, 2 \mathrm{H}), 1.54,1.72(\mathrm{~m}, 2 \mathrm{H}), 1.58(\mathrm{~d}, 3 \mathrm{H}, J=8.0 \mathrm{~Hz})$, $1.60(\mathrm{~s}, 3 \mathrm{H}), 1.78,2.16(\mathrm{~m}, 2 \mathrm{H}), 2.14,2.52(\mathrm{dd}, 2 \mathrm{H}$, $J=19.0,13.0 \mathrm{~Hz}, J=18.0,5.0 \mathrm{~Hz}), 2.18(\mathrm{~m}, 2 \mathrm{H}), 3.12(\mathrm{dd}$, $1 \mathrm{H}, J=12.0,4.0 \mathrm{~Hz}), 3.21(\mathrm{dd}, 1 \mathrm{H}, J=12.0,3.0 \mathrm{~Hz}), 3.34$ $(\mathrm{m}, 1 \mathrm{H}), 5.14(\mathrm{~d}, 1 \mathrm{H}, J=9.0 \mathrm{~Hz}), 5.53(\mathrm{q}, 1 \mathrm{H}, J=7.0 \mathrm{~Hz})$, $6.48(\mathrm{~s}, 1 \mathrm{H}) ;{ }^{13} \mathrm{C}-\mathrm{NMR}\left(75 \mathrm{MHz}, \mathrm{CDCl}_{3}\right) \delta 9.4,11.8,12.4$, $13.4,16.7,17.1,21.0,24.0,25.4,26.3,28.0,33.9,35.8$, $37.0,37.4,46.9,72.1,80.8,81.6,84.3,85.1,118.0,125.1$, $132.4,132.7,148.3,152.5,173.5,181.6,187.3$; HR FABMS $(\mathrm{m} / \mathrm{z})$ found: 528.3087, calcd: $528.3094\left(\mathrm{M}^{+}\right)$for $\mathrm{C}_{31} \mathrm{H}_{44} \mathrm{O}_{7}$.

4-Deacetyl-4- $O$ - $n$-butyryl stemphone $\mathrm{C}(\mathrm{C} 3 \mathrm{~b}):{ }^{1} \mathrm{H}-\mathrm{NMR}$ $\left(300 \mathrm{MHz}, \mathrm{CDCl}_{3}\right) \delta 0.84(\mathrm{t}, 3 \mathrm{H}, J=8.0 \mathrm{~Hz}), 0.88(\mathrm{~s}, 3 \mathrm{H})$, $1.03(\mathrm{~d}, 3 \mathrm{H}, J=7.0 \mathrm{~Hz}), 1.16(\mathrm{~s}, 3 \mathrm{H}), 1.18$ (s, 3H), 1.19, $1.88(\mathrm{~m}, 2 \mathrm{H}), 1.27(\mathrm{~s}, 3 \mathrm{H}), 1.28,1.54(\mathrm{~m}, 2 \mathrm{H}), 1.43(\mathrm{dd}$, $1 \mathrm{H}, J=13.0,4.5 \mathrm{~Hz}), 1.48,1.67(\mathrm{~m}, 2 \mathrm{H}), 1.55,1.75(\mathrm{~m}$, $2 \mathrm{H}), 1.59(\mathrm{~d}, 3 \mathrm{H}, J=7.0 \mathrm{~Hz}), 1.60(\mathrm{~s}, 3 \mathrm{H}), 1.78,2.18(\mathrm{~m}$, $2 \mathrm{H}), 2.12,2.51(\mathrm{dd}, 2 \mathrm{H}, J=19.0,13.0 \mathrm{~Hz}, J=18.0,4.5 \mathrm{~Hz}$ ), $2.16(\mathrm{~m}, 2 \mathrm{H}), 3.11(\mathrm{dd}, 1 \mathrm{H}, J=12.0,4.0 \mathrm{~Hz}), 3.21(\mathrm{dd}, 1 \mathrm{H}$, $J=12.0,3.0 \mathrm{~Hz}), 3.34(\mathrm{~m}, 1 \mathrm{H}), 5.14(\mathrm{~d}, 1 \mathrm{H}, J=9.0 \mathrm{~Hz})$, $5.54(\mathrm{q}, 1 \mathrm{H}, J=7.0 \mathrm{~Hz}), 6.48(\mathrm{~s}, 1 \mathrm{H}) ;{ }^{13} \mathrm{C}-\mathrm{NMR}(75 \mathrm{MHz}$, $\left.\mathrm{CDCl}_{3}\right) \delta 11.8,12.4,13.4,13.9,16.7,17.1,18.7,21.0$, $24.0,25.4,26.3,33.9,35.8,36.6,37.0,37.4,46.9,72.1$, $80.7,81.7,84.3,85.1,118.0,125.2,132.4,132.7,148.3$,
152.5, 172.7, 181.6, 187.3; HR FAB-MS $(\mathrm{m} / \mathrm{z})$ found: $542.3244\left(\mathrm{M}^{+}\right)$, calcd: $542.3263\left(\mathrm{M}^{+}\right)$for $\mathrm{C}_{32} \mathrm{H}_{46} \mathrm{O}_{7}$.

4-Deacetyl-4- $O$ - $n$-valeryl stemphone $\mathrm{C}(\mathrm{C} 3 \mathrm{c}):{ }^{1} \mathrm{H}-\mathrm{NMR}$ $\left(300 \mathrm{MHz}, \mathrm{CDCl}_{3}\right) \delta 0.84(\mathrm{t}, 3 \mathrm{H}, J=8.0 \mathrm{~Hz}), 0.88(\mathrm{~s}, 3 \mathrm{H})$, $1.02(\mathrm{~d}, 3 \mathrm{H}, J=7.0 \mathrm{~Hz}), 1.17(\mathrm{~s}, 3 \mathrm{H}), 1.18(\mathrm{~s}, 3 \mathrm{H}), 1.18$, $1.88(\mathrm{~m}, 2 \mathrm{H}), 1.20(\mathrm{~m}, 2 \mathrm{H}), 1.28(\mathrm{~s}, 3 \mathrm{H}), 1.41(\mathrm{dd}, 1 \mathrm{H}$, $J=13.0,4.5 \mathrm{~Hz}$ ), 1.47 (m, 2H), 1.47, 1.65 (m, 2H), 1.58, $1.78(\mathrm{~m}, 2 \mathrm{H}), 1.59$ (d, 3H, $J=8.0 \mathrm{~Hz}), 1.61(\mathrm{~s}, 3 \mathrm{H}), 1.78$, 2.18 (m, 2H), 2.12, $2.51(\mathrm{dd}, 2 \mathrm{H}, J=19.0,13.0 \mathrm{~Hz}, J=18.0$, $4.5 \mathrm{~Hz}), 2.17(\mathrm{~m}, 2 \mathrm{H}), 3.11(\mathrm{dd}, 1 \mathrm{H}, J=12.0,4.0 \mathrm{~Hz}), 3.20$ (dd, $1 \mathrm{H}, J=12.0,3.0 \mathrm{~Hz}), 3.35(\mathrm{dq}, 1 \mathrm{H}, J=9.0,7.0 \mathrm{~Hz}$ ), $5.14(\mathrm{~d}, 1 \mathrm{H}, J=9.0 \mathrm{~Hz}), 5.54(\mathrm{q}, 1 \mathrm{H}, J=7.0 \mathrm{~Hz}), 6.48(\mathrm{~s}$, $1 \mathrm{H}) ;{ }^{13} \mathrm{C}-\mathrm{NMR}\left(75 \mathrm{MHz}, \mathrm{CDCl}_{3}\right) \delta 11.8,12.4,13.4,14.0$, $16.7,17.1,21.0,22.4,24.0,25.4,26.3,27.3,33.9,34.4$, $35.8,37.0,37.4,46.9,72.1,80.7,81.7,84.3,85.1,118.0$, 125.2, 132.4, 132.7, 148.3, 152.5, 172.7, 181.6, 187.3; HR FAB-MS $(\mathrm{m} / \mathrm{z})$ found: $556.3391\left(\mathrm{M}^{+}\right)$, calcd: 556.3400 $\left(\mathrm{M}^{+}\right)$for $\mathrm{C}_{33} \mathrm{H}_{48} \mathrm{O}_{7}$.

4-Deacetyl-4- $O-n$-hexanoyl stemphone $\mathrm{C}(\mathrm{C} 3 \mathrm{~d}):{ }^{1} \mathrm{H}$ NMR $\left(300 \mathrm{MHz}, \mathrm{CDCl}_{3}\right) \delta 0.85(\mathrm{t}, 3 \mathrm{H}, J=8.0 \mathrm{~Hz}), 0.88(\mathrm{~s}$, $3 \mathrm{H}), 1.02(\mathrm{~d}, 3 \mathrm{H}, J=7.0 \mathrm{~Hz}), 1.16(\mathrm{~s}, 3 \mathrm{H}), 1.18(\mathrm{~s}, 3 \mathrm{H})$, $1.20,1.88(\mathrm{~m}, 2 \mathrm{H}), 1.20(\mathrm{~m}, 2 \mathrm{H}), 1.23(\mathrm{~m}, 2 \mathrm{H}), 1.27(\mathrm{~s}$, $3 \mathrm{H}), 1.41(\mathrm{dd}, 1 \mathrm{H}, J=13.0,4.5 \mathrm{~Hz}), 1.48(\mathrm{~m}, 2 \mathrm{H}), 1.48$, $1.65(\mathrm{~m}, 2 \mathrm{H}), 1.57,1.78(\mathrm{~m}, 2 \mathrm{H}), 1.59(\mathrm{~d}, 3 \mathrm{H}, J=7.0 \mathrm{~Hz})$, $1.61(\mathrm{~s}, 3 \mathrm{H}), 1.78,2.16(\mathrm{~m}, 2 \mathrm{H}), 2.08,2.51(\mathrm{dd}, 2 \mathrm{H}$, $J=19.0,13.0 \mathrm{~Hz}, J=18.0,4.5 \mathrm{~Hz}), 2.16(\mathrm{~m}, 2 \mathrm{H}), 3.11$ (dd, $1 \mathrm{H}, J=12.0,4.0 \mathrm{~Hz}), 3.20(\mathrm{dd}, 1 \mathrm{H}, J=12.0,3.0 \mathrm{~Hz}), 3.35$ (dq, $1 \mathrm{H}, J=9.0,7.0 \mathrm{~Hz}), 5.13(\mathrm{~d}, 1 \mathrm{H}, J=9.0 \mathrm{~Hz}), 5.54$ (q, $1 \mathrm{H}, J=7.0 \mathrm{~Hz}), 6.48(\mathrm{~s}, 1 \mathrm{H}) ;{ }^{13} \mathrm{C}-\mathrm{NMR}\left(75 \mathrm{MHz} \mathrm{CDCl}_{3}\right) \delta$ $11.8,12.4,13.4,14.2,16.7,17.2,21.6,22.6,24.9,25.4$, $26.3,31.4,33.7,34.7,35.8,37.0,37.4,46.9,72.1,80.7$, $81.7,84.3,85.1,118.0,125.3,132.4,132.7,148.4,152.5$, 172.9, 181.6, 187.3; HR FAB-MS $(\mathrm{m} / \mathrm{z})$ found: 570.3544 $\left(\mathrm{M}^{+}\right)$, calcd: $570.3557\left(\mathrm{M}^{+}\right)$for $\mathrm{C}_{34} \mathrm{H}_{50} \mathrm{O}_{7}$.

4-Deacetyl-4-O-benzoyl stemphone $\mathrm{C}(\mathrm{C} 3 \mathrm{e}):{ }^{1} \mathrm{H}-\mathrm{NMR}$ $\left(300 \mathrm{MHz}, \mathrm{CDCl}_{3}\right) \delta 0.85(\mathrm{~s}, 3 \mathrm{H}), 1.10(\mathrm{~d}, 3 \mathrm{H}, J=6.0 \mathrm{~Hz})$, $1.15(\mathrm{~s}, 3 \mathrm{H}), 1.17(\mathrm{~s}, 3 \mathrm{H}), 1.12,1.84(\mathrm{~m}, 2 \mathrm{H}), 1.24(\mathrm{~s}, 3 \mathrm{H})$, $1.26(\mathrm{dd}, 1 \mathrm{H}, J=13.0,5.0 \mathrm{~Hz}), 1.45,1.62(\mathrm{~m}, 2 \mathrm{H}), 1.58$, $1.76(\mathrm{~m}, 2 \mathrm{H}), 1.59$ (d, 3H, $J=8.0 \mathrm{~Hz}), 1.70(\mathrm{~s}, 3 \mathrm{H}), 1.75$, $2.16(\mathrm{~m}, 2 \mathrm{H}), 2.03,2.42(\mathrm{dd}, 2 \mathrm{H}, J=19.0,13.0 \mathrm{~Hz}, J=19.0$, $5.0 \mathrm{~Hz}), 3.06(\mathrm{dd}, 1 \mathrm{H}, J=13.0,4.0 \mathrm{~Hz}), 3.18(\mathrm{dd}, 1 \mathrm{H}$, $J=12.0,3.0 \mathrm{~Hz}), 3.12(\mathrm{dq}, 1 \mathrm{H}), 5.34$ (d, $1 \mathrm{H}, J=7.0 \mathrm{~Hz})$, $5.67(\mathrm{q}, 1 \mathrm{H}, J=7.0 \mathrm{~Hz}), 6.55(\mathrm{~s}, 1 \mathrm{H}), 7.40(\mathrm{t}, 2 \mathrm{H}$, $J=5.0 \mathrm{~Hz}), 7.54$ (t, $1 \mathrm{H}, J=5.0 \mathrm{~Hz}), 7.90$ (d, 2H, $J=5.0 \mathrm{~Hz})$; ${ }^{13} \mathrm{C}-\mathrm{NMR}\left(75 \mathrm{MHz}, \mathrm{CDCl}_{3}\right) \delta 11.7,12.4,13.4,16.6,16.9$, 21.0, 21.6, 24.0, 25.4, 26.3, 33.5, 35.8, 36.9, 37.4, 46.7, $72.1,80.7,83.3,84.2,85.1,118.1,125.9,128.6,128.6$, $129.9,129.9,130.4,132.3,132.5,133.1,148.5,152.5$, 165.5, 181.8, 187.2; HR FAB-MS $(\mathrm{m} / \mathrm{z})$ found: 576.3087 $(\mathrm{M})^{+}$, calcd: $576.3087\left(\mathrm{M}^{+}\right)$for $\mathrm{C}_{35} \mathrm{H}_{44} \mathrm{O}_{7}$. 


\section{Preparation of Methoxy Derivatives (E1 and G1)}

To a solution of stemphone $\mathrm{E}(5.3 \mathrm{mg}, 0.010 \mathrm{mmol})$ in $\mathrm{MeOH}(340 \mu \mathrm{l}) \mathrm{TMS}-$ diazomethane $(170 \mu \mathrm{l}, 0.10 \mathrm{mmol})$ was added. After stirring at $40^{\circ} \mathrm{C}$ for 24 hours, the reaction mixture was concentrated in vacuo to dryness to give a brown material. This material was purified by preparative HPLC to give 10-methoxy stemphone E (E1, $1.0 \mathrm{mg}, 19 \%)$ as a white powder. Similarly, 7,10-dimethoxy stemphone $\mathrm{G}$ (G1) was prepared from stemphone $\mathrm{G}$.

10-Methoxy stemphone E (E1): ${ }^{1} \mathrm{H}-\mathrm{NMR}(300 \mathrm{MHz}$, $\left.\mathrm{CDCl}_{3}\right) \delta 1.00(\mathrm{~s}, 3 \mathrm{H}), 1.08(\mathrm{~d}, 3 \mathrm{H}, J=7.0 \mathrm{~Hz}), 1.15(\mathrm{~s}$, $3 \mathrm{H}), 1.21(\mathrm{~s}, 3 \mathrm{H}), 1.25(\mathrm{~s}, 3 \mathrm{H}), 1.56,1.92(\mathrm{~m}, 2 \mathrm{H}), 1.60$, $1.80(\mathrm{~m}, 2 \mathrm{H}), 1.64$ (d, 3H, J=8.0 Hz), 1.67 (s, 3H), 1.80 (s, $3 \mathrm{H}), 1.92(\mathrm{~m}, 2 \mathrm{H}), 2.35(\mathrm{~d}, 1 \mathrm{H}, J=10.0 \mathrm{~Hz}), 3.43(\mathrm{dq}, 1 \mathrm{H}$, $J=10.0,7.0 \mathrm{~Hz}), 3.60(\mathrm{dd}, 1 \mathrm{H}, J=13.0,4.0 \mathrm{~Hz}), 3.74(\mathrm{dd}$, $1 \mathrm{H}, J=13.0,5.0 \mathrm{~Hz}), 4.12$ (brt, $1 \mathrm{H}), 5.06(\mathrm{~d}, 1 \mathrm{H}$, $J=10.0 \mathrm{~Hz}), 5.45(\mathrm{~d}, 1 \mathrm{H}, J=10.0 \mathrm{~Hz}), 5.67(\mathrm{q}, 1 \mathrm{H}$, $J=8.0 \mathrm{~Hz}), 6.27(\mathrm{~s}, 1 \mathrm{H}) ;{ }^{13} \mathrm{C}-\mathrm{NMR}\left(75 \mathrm{MHz}, \mathrm{CDCl}_{3}\right) \delta$ $11.3,13.3,13.4,17.6,21.4,22.3,23.9,25.4,26.6,28.4$, $34.0,37.8,40.8,46.9,55.7,63.5,71.0,72.0,77.3,79.7$, $80.9,82.5,101.2,112.2,125.6,128.6,132.8,137.9,140.1$, 150.3, 170.4; HR FAB-MS $(\mathrm{m} / \mathrm{z})$ found: 563.3153 $(\mathrm{M}+\mathrm{H})^{+}$, calcd: $563.3153(\mathrm{M}+\mathrm{H})^{+}$for $\mathrm{C}_{31} \mathrm{H}_{47} \mathrm{O}_{9}$.

7,10-Dimethoxy stemphone $\mathrm{G} \quad(\mathrm{G} 1):{ }^{1} \mathrm{H}-\mathrm{NMR}$ $\left(300 \mathrm{MHz}, \mathrm{CDCl}_{3}\right) \delta 1.05(\mathrm{~d}, 3 \mathrm{H}, J=7 \mathrm{~Hz}), 1.13(\mathrm{~s}, 3 \mathrm{H})$, 1.15 (s, 3H), 1.19 (s, 3H), 1.46, $2.01(\mathrm{~m}, 2 \mathrm{H}), 1.48(\mathrm{~s}, 3 \mathrm{H})$, 1.58, $1.82(\mathrm{~m}, 2 \mathrm{H}), 1.65(\mathrm{~d}, 3 \mathrm{H}, J=9.0 \mathrm{~Hz}), 1.66(\mathrm{~s}, 3 \mathrm{H})$, $1.79(\mathrm{~s}, 3 \mathrm{H}), 2.05(\mathrm{~m}, 2 \mathrm{H}), 3.35(\mathrm{~s}, 1 \mathrm{H}), 3.60(\mathrm{dd}, 1 \mathrm{H}$, $J=13.0,4.0 \mathrm{~Hz}), 3.69$ (dd, 1H, $J=13.0,5.0 \mathrm{~Hz}), 3.79$ (s, $3 \mathrm{H}), 3.84$ (s, 3H), 4.75 (brt, $1 \mathrm{H}, J=6.0 \mathrm{~Hz}), 5.34$ (d, 1H, $J=9.5 \mathrm{~Hz}$ ), 5.69 (q, $1 \mathrm{H}, J=9.0 \mathrm{~Hz}), 6.28(\mathrm{~s}, 1 \mathrm{H}) ;{ }^{13} \mathrm{C}-\mathrm{NMR}$ $\left(75 \mathrm{MHz}, \mathrm{CDCl}_{3}\right) \delta 11.2,13.4,13.5,18.6,21.4,21.9,24.0$, 25.0, 26.3, 29.7, 34.5, 37.7, 40.2, 53.7, 56.2, 61.1, 70.0, $72.0,76.0,79.6,82.5,82.7,100.7,110.9,126.2,132.5$, $140.7,144.7,153.5,155.9,170.1,193.0$; HR FAB-MS $(\mathrm{m} / \mathrm{z})$ found: $575.3220(\mathrm{M}+\mathrm{H})^{+}$, calcd: $575.3226(\mathrm{M}+\mathrm{H})^{+}$ for $\mathrm{C}_{32} \mathrm{H}_{47} \mathrm{O}_{9}$.

\section{Preparation of 7,10-Diacetyl Stemphone C (C4)}

To a solution of stemphone $\mathrm{C}(10 \mathrm{mg}, 0.019 \mathrm{mmol})$ in $\mathrm{MeOH}(500 \mu \mathrm{l})$ sodium borohydride $(5.5 \mathrm{mg}, 0.145 \mathrm{mmol})$ was added, and the resulting solution was stirred at room temperature. After 10 minutes, the mixture was concentrated in vacuo. The residue was dissolved in $\mathrm{CH}_{2} \mathrm{Cl}_{2}(500 \mu \mathrm{l})$, and acetic anhydride $(15 \mu \mathrm{l}, 0.11 \mathrm{mmol})$, triethylamine $(15 \mu 1,0.16 \mathrm{mmol})$ and 4 -(dimethylamino) pyridine $(1.0 \mathrm{mg}, 0.0080 \mathrm{mmol})$ were added to the solution. The resulting mixture was stirred at $40^{\circ} \mathrm{C}$ for 10 hours, and diluted with $1.0 \mathrm{~N} \mathrm{HCl}$, and the aqueous phase was extracted with EtOAc. The organic layer was recovered, dried over anhydrous $\mathrm{Na}_{2} \mathrm{SO}_{4}$, filtered and concentrated in vacuo to dryness. The residue was purified by preparative HPLC (column; PEGASIL ODS, $20 \times 250 \mathrm{~mm}$; solvent, $80 \% \mathrm{CH}_{3} \mathrm{CN}$; detection, $\mathrm{UV}$ at $210 \mathrm{~nm}$; flow rate, $6.0 \mathrm{ml} / \mathrm{minute})$ to give 7,10 -diacetyl stemphone $\mathrm{C}$ (C4, $1.4 \mathrm{mg}, 14.0 \%$ ) as a white powder.

7,10-Diacetyl-stemphone C (C4): ${ }^{1} \mathrm{H}-\mathrm{NMR}(300 \mathrm{MHz}$, $\left.\mathrm{CDCl}_{3}\right) \delta 0.88(\mathrm{~s}, 3 \mathrm{H}), 1.01(\mathrm{~d}, 3 \mathrm{H}, J=7.5 \mathrm{~Hz}), 1.17(\mathrm{~s}$, $3 \mathrm{H}), 1.19(\mathrm{~s}, 3 \mathrm{H}), 1.20(\mathrm{~s}, 3 \mathrm{H}), 1.22,1.84(\mathrm{~m}, 2 \mathrm{H}), 1.44(\mathrm{~m}$, $1 \mathrm{H}), 1.44,1.66(\mathrm{~m}, 2 \mathrm{H}), 1.60(\mathrm{~s}, 3 \mathrm{H}), 1.61(\mathrm{~d}, 3 \mathrm{H}$, $J=7.0 \mathrm{~Hz}), 1.63,1.80(\mathrm{~m}, 2 \mathrm{H}), 1.74,2.00(\mathrm{~m}, 2 \mathrm{H}), 1.83(\mathrm{~s}$, $3 \mathrm{H}), 2.28,2.48(\mathrm{~m}, 2 \mathrm{H}), 2.29(\mathrm{~s}, 3 \mathrm{H}), 2.30(\mathrm{~s}, 3 \mathrm{H}), 3.13$ (dd, $1 \mathrm{H}, J=13.0,4.0 \mathrm{~Hz}), 3.21(\mathrm{dd}, 1 \mathrm{H}, J=13.0,3.0 \mathrm{~Hz}$ ), $3.23(\mathrm{~m}, 1 \mathrm{H}), 5.22(\mathrm{~d}, 1 \mathrm{H}, J=10.0 \mathrm{~Hz}), 5.59(\mathrm{q}, 1 \mathrm{H}$, $J=7.0 \mathrm{~Hz}), 6.50$ (s $1 \mathrm{H}) ;{ }^{13} \mathrm{C}-\mathrm{NMR}\left(75 \mathrm{MHz}, \mathrm{CDCl}_{3}\right) \delta$ $11.5,12.3,13.4,17.8,18.1,20.7,20.7,21.0,21.1,21.6$, $23.9,25.4,26.4,34.6,35.6,36.8,37.8,46.7,72.1,80.8$, $82.5,84.5,85.0,111.2,114.5,125.7,132.4,136.1,145.8$, 146.8, 168.8, 169.0, 170.5; HR FAB-MS $(\mathrm{m} / \mathrm{z})$ found: 623.3230, calcd: $623.3196(\mathrm{M}+\mathrm{Na})^{+}$for $\mathrm{C}_{34} \mathrm{H}_{48} \mathrm{O}_{9} \mathrm{Na}$.

\section{Preparation of 7,10,12,19,23-Pentaacetyl Stemphone E (E4)}

To a solution of stemphone $\mathrm{E}(10 \mathrm{mg}, 0.011 \mathrm{mmol})$ in $\mathrm{CH}_{2} \mathrm{Cl}_{2}(500 \mu \mathrm{l})$ acetic anhydride $(15 \mu \mathrm{l}, 0.16 \mathrm{mmol})$, triethylamine $(15 \mu \mathrm{l}, 0.11 \mathrm{mmol})$ and 4 -(dimethylamino) pyridine $(1.0 \mathrm{mg}, 0.0080 \mathrm{mmol})$ were added, and the resulting solution was stirred at $40^{\circ} \mathrm{C}$ for 10 hours. The reaction mixture was diluted with $1.0 \mathrm{~N} \mathrm{HCl}$, and the aqueous phase was extracted with EtOAc. The organic layer was recovered, dried over anhydrous $\mathrm{Na}_{2} \mathrm{SO}_{4}$, filtered and concentrated in vacuo to dryness. The product was purified by preparative HPLC (column; PEGASIL ODS, $20 \times 250 \mathrm{~mm}$; solvent, $80 \% \mathrm{CH}_{3} \mathrm{CN}$; detection, $\mathrm{UV}$ at $210 \mathrm{~nm}$; flow rate, $6.0 \mathrm{ml} / \mathrm{minute}$ ) to give 7,10,12,19,23pentaacetyl stemphone $\mathrm{E}(\mathrm{E} 4,6.4 \mathrm{mg}, 64 \%)$ as a white powder.

7,10,12,19,23-Pentaacetyl-methoxy stemphone E (E4): ${ }^{1} \mathrm{H}-\mathrm{NMR}\left(300 \mathrm{MHz}, \mathrm{CDCl}_{3}\right) \delta 1.01(\mathrm{~d}, 3 \mathrm{H}, J=7.5 \mathrm{~Hz})$, $1.12(\mathrm{~s}, 3 \mathrm{H}), 1.27(\mathrm{~s}, 3 \mathrm{H}), 1.42(\mathrm{~s}, 3 \mathrm{H}), 1.44(\mathrm{~s}, 3 \mathrm{H}), 1.60$ (s, 3H), 1.62 (d, 3H, J=7.0 Hz), 1.62, $1.74(\mathrm{~m}, 2 \mathrm{H}), 1.64$, $1.88(\mathrm{~m}, 2 \mathrm{H}), 1.84(\mathrm{~m}, 2 \mathrm{H}), 1.83$ (s, 3H), 1.96 (s, 3H), 2.03 (s, 3H), 2.09 (s, 3H), $2.22(\mathrm{~s}, 3 \mathrm{H}), 2.31(\mathrm{~s}, 3 \mathrm{H}), 2.59(\mathrm{~d}, 1 \mathrm{H}$, $J=10.0 \mathrm{~Hz}), 3.20(\mathrm{dq}, 1 \mathrm{H}, J=10.0,7.5 \mathrm{~Hz}), 3.68$ (dd, $1 \mathrm{H}$, $J=13.0,4.0 \mathrm{~Hz}$ ), 3.87 (dd, $1 \mathrm{H}, J=13.0,3.0 \mathrm{~Hz}), 4.59$ (brt, $1 \mathrm{H}, J=3.0 \mathrm{~Hz}), 5.16(\mathrm{~d}, 1 \mathrm{H}, J=10.0 \mathrm{~Hz}), 5.60(\mathrm{q}, 1 \mathrm{H}$, $J=7.0 \mathrm{~Hz}), 6.21(\mathrm{~d}, 1 \mathrm{H}, J=10.0 \mathrm{~Hz}), 6.46(\mathrm{~s} 1 \mathrm{H}) ;{ }^{13} \mathrm{C}-\mathrm{NMR}$ $\left(75 \mathrm{MHz}, \mathrm{CDCl}_{3}\right) \delta 11.3,12.5,13.4,17.6,20.7,21.3,21.6$, $21.7,21.7,21.7,22.3,22.6,23.0,25.0,25.6,35.2,37.2$, $39.7,44.5,65.8,67.0,73.2,77.1,77.7,80.8,82.8,113.5$, $116.8,126.1,132.2,136.3,137.5,146.6,146.9,168.5$, $169.5,170.4,170.5,170.6,172.7$; HR FAB-MS $(\mathrm{m} / \mathrm{z})$ 
found: 781.3405, calcd: $781.3411(\mathrm{M}+\mathrm{Na})^{+}$for $\mathrm{C}_{40} \mathrm{H}_{54} \mathrm{O}_{14} \mathrm{Na}$.

\section{Preparation of 12-Dehydroxy-13-dehydro Stemphone E and 12-Dehydroxy-13-dehydro Stemphone B (E2 and E3)}

Stemphone E $(50 \mathrm{mg})$ was dehydrated by heating at $60^{\circ} \mathrm{C}$ for 1 hour in $\mathrm{CHCl}_{3}$. Two main products were purified with preparative HPLC (column; PEGASIL ODS, $20 \times 250 \mathrm{~mm}$; solvent, $80 \% \mathrm{CH}_{3} \mathrm{CN}$; detection, $\mathrm{UV}$ at $210 \mathrm{~nm}$; flow rate, $6.0 \mathrm{ml} / \mathrm{minute)}$ to give 12-dehydroxy-13-dehydro stemphone E (E2, $12.0 \mathrm{mg}, 71.0 \%$ ) and 12-dehydroxy-13dehydro stemphone B (E3, $2.3 \mathrm{mg}, 14.0 \%)$ as white and red powders, respectively.

12-Dehydroxy-13-dehydro stemphone E (E2): ${ }^{1} \mathrm{H}-\mathrm{NMR}$ $\left(300 \mathrm{MHz}, \mathrm{CDCl}_{3}\right) \delta 1.02(\mathrm{~d}, 3 \mathrm{H}, J=7.5 \mathrm{~Hz}), 1.14(\mathrm{~s}, 3 \mathrm{H})$, $1.18(\mathrm{~s}, 3 \mathrm{H}), 1.22(\mathrm{~s}, 3 \mathrm{H}), 1.64(\mathrm{~d}, 3 \mathrm{H}, J=7.0 \mathrm{~Hz}), 1.67$ (s, $3 \mathrm{H}), 1.70(\mathrm{~m}, 2 \mathrm{H}), 1.80,2.01(\mathrm{~m}, 2 \mathrm{H}), 1.82$ (s, 3H), 1.96, 2.12 (m, 2H), 3.45 (dq, 1H, $J=10.0,7.5 \mathrm{~Hz}), 3.64$ (dd, 1H, $J=13.0,4.0 \mathrm{~Hz}), 3.86(\mathrm{dd}, 1 \mathrm{H}, J=13.0,3.0 \mathrm{~Hz}), 4.28$ (brt, $1 \mathrm{H}), 5,41$ (d, $1 \mathrm{H}, J=10.0 \mathrm{~Hz}), 5.66(\mathrm{q}, 1 \mathrm{H}, J=7.0 \mathrm{~Hz}), 6.22$ $(\mathrm{s}, 1 \mathrm{H}), 6.60(\mathrm{~s}, 1 \mathrm{H}) ;{ }^{13} \mathrm{C}-\mathrm{NMR}\left(75 \mathrm{MHz}, \mathrm{CDCl}_{3}\right) \delta 11.0$, $13.2,17.6,20.5,21.3,23.8,24.0,26.3,26.6,27.9,34.6$, $37.1,44.3,69.3,71.9,74.5,77.9,78.9,82.8,105.9,108.8$, $113.7,125.7,130.0,132.5,136.6,138.3,139.5,144.2$, 170.9 HR FAB-MS $(\mathrm{m} / \mathrm{z})$ found: $531.2896(\mathrm{M}+\mathrm{H})^{+}$, calcd: $531.2980(\mathrm{M}+\mathrm{H})^{+}$for $\mathrm{C}_{30} \mathrm{H}_{43} \mathrm{O}_{8}$.

12-Dehydroxy-13-dehydro stemphone B (E3): ${ }^{1} \mathrm{H}-\mathrm{NMR}$ $\left(300 \mathrm{MHz}, \mathrm{CDCl}_{3}\right) \delta 0.98(\mathrm{~d}, 3 \mathrm{H}, J=7.5 \mathrm{~Hz}), 1.08(\mathrm{~s}, 3 \mathrm{H})$, $1.10(\mathrm{~s}, 3 \mathrm{H}), 1.15(\mathrm{~s}, 3 \mathrm{H}), 1.53(\mathrm{~d}, 3 \mathrm{H}, J=7.0 \mathrm{~Hz}), 1.56(\mathrm{~s}$, $3 \mathrm{H}), 1.70(\mathrm{~m}, 2 \mathrm{H}), 1.64,1.80(\mathrm{~m}, 2 \mathrm{H}), 1.70,2.01(\mathrm{~m}, 2 \mathrm{H})$, 1.96, 2.20 (m, 2H), 1.88 (s, 3H), 3.27 (dq, 1H, $J=10.0$, $7.5 \mathrm{~Hz}), 3.55$ (dd, $1 \mathrm{H}, J=13.0,4.0 \mathrm{~Hz}), 3.77(\mathrm{dd}, 1 \mathrm{H}$, $J=13.0,3.0 \mathrm{~Hz}), 4.22$ (brt, $1 \mathrm{H}), 5,10$ (d, $1 \mathrm{H}, J=10.0 \mathrm{~Hz})$, $5.49(\mathrm{q}, 1 \mathrm{H}, J=7.0 \mathrm{~Hz}), 6.34(\mathrm{~s}, 1 \mathrm{H}), 6.42(\mathrm{~s}, 1 \mathrm{H}) ;{ }^{13} \mathrm{C}-$
NMR $\left(75 \mathrm{MHz}, \mathrm{CDCl}_{3}\right) \delta 11.5,13.2,17.1,20.8,21.1,23.9$, 24.0, 26.3, 26.6, 28.2, 34.1, 36.7, 44.8, 69.1, 71.8, 73.8, $77.2,78.9,81.0,81.5,111.5,117.0,125.3,131.6,131.8$, 143.5, 149.0, 149.3, 170.0, 180.8, 184.6 HR FAB-MS $(\mathrm{m} / \mathrm{z})$ found: $529.2723(\mathrm{M}+\mathrm{H})^{+}$, calcd: $529.2720(\mathrm{M}+\mathrm{H})^{+}$for $\mathrm{C}_{30} \mathrm{H}_{41} \mathrm{O}_{8}$.

\section{Assay for Potentiation of Imipenem Activity against MRSA}

Assay for potentiation of imipenem activity against MRSA was carried out by the paper disk method and the liquid microdilution method as previously reported [3].

\section{Assay for Cytotoxicity}

Cytotoxicity of stemphones to Jurkat cells was evaluated by the MTT assay [5]. Cells $\left(2 \times 10^{4}\right.$ cells/100 $\mu \mathrm{l} /$ well $)$ were cultured in 96-well plates (Corning) in the presence of stemphones at the indicated concentrations at $37^{\circ} \mathrm{C}$ for 48 hours after which they received MTT solution (SIGMA, $10 \mu \mathrm{l}$ to each well, $5.5 \mathrm{mg} / \mathrm{ml}$ in phosphate buffered saline (PBS)) and incubated at $37^{\circ} \mathrm{C}$ for 4 hours. A $90-\mu 1$ aliquot of the extraction solution $(40 \% \quad(\mathrm{v} / \mathrm{v}) \quad \mathrm{N}, \mathrm{N}$ dimethylformamide, $2.0 \%$ (v/v) $\mathrm{CH}_{3} \mathrm{COOH}, 20 \%(\mathrm{w} / \mathrm{v})$ SDS and $0.03 \mathrm{~N} \mathrm{HCl}$ ) was added to each well, and the cells were incubated at room temperature for 2 hours. Cytotoxicity was determined by measuring optical density at $550 \mathrm{~nm}$ with a plate reader (Bio-Tek instruments).

\section{Results}

\section{Structural Elucidation}

Physico-chemical properties of the isolated stemphones are summarized in Table 1. Stemphone D showed similar UV absorption maxima at $265 \mathrm{~nm}$ to stemphones $\mathrm{B}$ and $\mathrm{C}$,

Table 1 Physico-chemical properties of stemphones D, E, F and G

\begin{tabular}{|c|c|c|c|c|}
\hline & Stemphone D & Stemphone E & Stemphone F & Stemphone G \\
\hline Appearance & Yellow powder & White powder & Yellow powder & Yellow powder \\
\hline Molecular weight & 530 & 548 & 604 & 546 \\
\hline $\begin{array}{l}\text { Molecular formula } \\
\text { HRFAB-MS (m/z) }\end{array}$ & $\mathrm{C}_{30} \mathrm{H}_{42} \mathrm{O}_{8}$ & $\mathrm{C}_{30} \mathrm{H}_{44} \mathrm{O}_{9}$ & $\mathrm{C}_{33} \mathrm{H}_{48} \mathrm{O}_{10}$ & $\mathrm{C}_{30} \mathrm{H}_{42} \mathrm{O}_{9}$ \\
\hline Calcd.: & $553.2777(\mathrm{M}+\mathrm{Na})^{+}$ & $549.2986(\mathrm{M}+\mathrm{H})^{+}$ & $627.3146(\mathrm{M}+\mathrm{Na})^{+}$ & $545.2734(\mathrm{M}-\mathrm{H})^{-}$ \\
\hline Found: & 553.2788 & 549.2977 & 627.3151 & 545.2751 \\
\hline UV (MeOH) $\lambda_{\max } \mathrm{nm}(\varepsilon)$ & $\begin{array}{l}203 \text { (17442), } 265 \text { (8284), } \\
\quad 396 \text { (678) }\end{array}$ & $\begin{array}{l}204 \text { (34447), } 292 \text { (4370), } \\
\quad 356 \text { (403) }\end{array}$ & $\begin{array}{r}201 \text { (11669), } 244 \text { (6427), } \\
288 \text { (3603), } 361 \text { (387) }\end{array}$ & $\begin{array}{l}212(10647), 242 \text { (4368), } \\
282(7644), 380 \text { (2457) }\end{array}$ \\
\hline$[\alpha]_{D}^{26}$ & $+93.0^{\circ}(c=0.1, \mathrm{MeOH})$ & $+100.8^{\circ}(c=0.1, \mathrm{MeOH})$ & $+148.9^{\circ}(c=0.1, \mathrm{MeOH})$ & $+72.5^{\circ}(c=0.1, \mathrm{MeOH})$ \\
\hline $\mathrm{IR}(\mathrm{KBr}) v_{\max }\left(\mathrm{cm}^{-1}\right)$ & $\begin{array}{l}3442,2973,1735 \\
1643,1604\end{array}$ & $3434,2929,1718,1629$ & $\begin{array}{l}3438,2967,1658 \\
1629,1623\end{array}$ & $\begin{array}{l}3428,2925,1729 \\
1639\end{array}$ \\
\hline
\end{tabular}


Table $2{ }^{1} \mathrm{H}$ - and ${ }^{13} \mathrm{C}-\mathrm{NMR}$ chemical shifts of stemphones

\begin{tabular}{|c|c|c|c|c|c|c|}
\hline \multirow{2}{*}{ Position } & \multicolumn{2}{|c|}{ Stemphone B } & \multicolumn{2}{|c|}{ Stemphone C } & \multicolumn{2}{|c|}{ Stemphone D } \\
\hline & $\delta_{\mathrm{C}}$ & $\delta_{\mathrm{H}}(\mathrm{J} \mathrm{Hz})$ & $\delta_{\mathrm{C}}$ & $\delta_{\mathrm{H}}(\mathrm{J} \mathrm{Hz})$ & $\delta_{\mathrm{C}}$ & $\delta_{\mathrm{H}}(\mathrm{J} \mathrm{Hz})$ \\
\hline 1 & $13.2 \mathrm{q}$ & $1.61 \mathrm{~d}, \mathrm{br}(7.0)$ & $13.1 \mathrm{q}$ & $1.59 \mathrm{~d}, \mathrm{br}(7.0)$ & 12.8 & $1.60 \mathrm{~d}(7.0)$ \\
\hline 2 & $125.3 d$ & $5.56 \mathrm{q}, \mathrm{br}(7.0)$ & $124.9 d$ & $5.53 \mathrm{q}(7.0)$ & 125.0 & $5.55 q(7.0)$ \\
\hline 3 & $131.7 \mathrm{~s}$ & - & $132.1 \mathrm{~s}$ & - & 132.4 & - \\
\hline 4 & $81.4 d$ & $5.15 d(8.5)$ & $81.5 d$ & $5.14 d(8.5)$ & 81.6 & $5.14 d(9.0)$ \\
\hline 5 & $34.2 \mathrm{~d}$ & $3.30 \mathrm{dq}(8.5,7.0)$ & $33.5 d$ & $3.34 \mathrm{dq}(8.5,7.0)$ & 33.4 & $3.34 \mathrm{dq}(9.0,7.5)$ \\
\hline 6 & $148.8 \mathrm{~s}$ & - & $148.0 \mathrm{~s}$ & - & 148.0 & - \\
\hline 7 & $181.0 \mathrm{~s}$ & - & $181.3 \mathrm{~s}$ & - & 181.3 & - \\
\hline 8 & $151.5 \mathrm{~s}$ & - & $152.3 \mathrm{~s}$ & - & 152.4 & - \\
\hline 9 & $117.8 \mathrm{~s}$ & - & $117.8 \mathrm{~s}$ & - & 117.7 & - \\
\hline 10 & $188.5 \mathrm{~s}$ & - & $187.1 \mathrm{~s}$ & - & 187.2 & - \\
\hline \multicolumn{7}{|l|}{$10-\mathrm{OH}$} \\
\hline 11 & $132.6 \mathrm{~d}$ & $6.47 \mathrm{~s}$ & $132.4 d$ & $6.48 d(1.0)$ & 132.4 & $6.48 \mathrm{~s}$ \\
\hline \multirow[t]{2}{*}{12} & $62.3 d$ & $4.90 \mathrm{~d}(11.0)$ & $16.4 \mathrm{t}$ & $2.11 \mathrm{dd}(19.0,13.0)$ & 16.1 & $2.12,2.50 \mathrm{~m}$ \\
\hline & & & & $2.52 \mathrm{dd}(19.0,5.0)$ & & \\
\hline $12-\mathrm{OH}^{\mathrm{a}}$ & - & $3.42, \mathrm{br}$ & - & - & - & - \\
\hline 13 & $45.4 d$ & $2.23 d(11.0)$ & $46.6 d$ & $1.43 \mathrm{dd}(13.0,5.0)$ & 38.9 & $2.12 \mathrm{~m}$ \\
\hline 14 & $83.8 \mathrm{~s}$ & - & $80.5 \mathrm{~s}$ & - & 81.0 & - \\
\hline 15 & $37.1 \mathrm{t}$ & $1.88 \mathrm{~m}, 2.08 \mathrm{~m}$ & $37.2 \mathrm{t}$ & $1.79 \mathrm{~m}, 2.18 \mathrm{~m}$ & 36.7 & $1.82 \mathrm{~m}, 2.15 \mathrm{~m}$ \\
\hline 16 & $25.0 t$ & $1.58 \mathrm{~m}, 1.86 \mathrm{~m}$ & $25.2 t$ & $1.63 \mathrm{~m}, 1.80 \mathrm{~m}$ & 24.9 & 1.66 m, 1.82 m \\
\hline 17 & $76.2 d$ & $3.68 \mathrm{dd}(13.0,4.0)$ & $84.0 \mathrm{~d}$ & $3.12 \mathrm{dd}(12.0,4.0)$ & 75.9 & $3.70 \mathrm{dd}(12.0,3.5)$ \\
\hline 18 & $40.8 \mathrm{~s}$ & - & $35.5 \mathrm{~s}$ & - & 39.7 & - \\
\hline 19 & $70.7 d$ & $4.10 \mathrm{t}, \mathrm{br}(3.0)$ & $36.8 \mathrm{t}$ & $1.21 \mathrm{~m}, 1.86 \mathrm{~m}$ & 69.3 & $3.90 \mathrm{t}, \mathrm{br}(3.0)$ \\
\hline $19-\mathrm{OH}^{\mathrm{a}}$ & - & $4.13, \mathrm{br}$ & - & - & - & - \\
\hline 20 & $28.2 t$ & $1.60 \mathrm{~m}, 1.96 \mathrm{~m}$ & $21.3 t$ & $1.48 \mathrm{~m}, 1.66 \mathrm{~m}$ & 29.9 & $1.48 \mathrm{~m}, 2.00 \mathrm{~m}$ \\
\hline 21 & $79.6 d$ & $3.57 \mathrm{dd}(13.0,3.0)$ & $84.9 d$ & $3.21 \mathrm{dd}(12.0,3.0)$ & 78.9 & $3.58 \mathrm{dd}(12.5,3.0)$ \\
\hline 22 & $71.7 \mathrm{~s}$ & - & $71.8 \mathrm{~s}$ & - & 71.8 & - \\
\hline 23 & $23.8 q$ & $1.14 \mathrm{~s}$ & $23.8 \mathrm{q}$ & $1.16 \mathrm{~s}$ & 23.8 & $1.15 \mathrm{~s}$ \\
\hline 24 & $26.4 \mathrm{q}$ & $1.20 \mathrm{~s}$ & $26.1 \mathrm{q}$ & $1.18 \mathrm{~s}$ & 26.2 & $1.20 \mathrm{~s}$ \\
\hline 25 & $13.1 \mathrm{q}$ & $0.98 \mathrm{~s}$ & $12.2 \mathrm{q}$ & $0.88 \mathrm{~s}$ & 13.1 & $0.89 \mathrm{~s}$ \\
\hline 26 & $21.3 q$ & $1.32 \mathrm{~s}$ & $20.8 q$ & $1.28 \mathrm{~s}$ & 20.9 & $1.29 \mathrm{~s}$ \\
\hline 27 & $16.9 q$ & $1.04 \mathrm{~d}(7.0)$ & $17.0 \mathrm{q}$ & $1.02 \mathrm{~d}(7.0)$ & 17.1 & $1.02 \mathrm{~d}(7.5)$ \\
\hline 28 & $11.6 \mathrm{q}$ & $1.62 \mathrm{~s}$ & $11.6 \mathrm{q}$ & $1.62 \mathrm{~s}, \mathrm{br}$ & 11.6 & $1.61 \mathrm{~s}$ \\
\hline 29 & $169.7 \mathrm{~s}$ & - & $169.7 \mathrm{~s}$ & - & 169.9 & - \\
\hline 30 & $21.2 \mathrm{q}$ & $1.94 \mathrm{~s}$ & $21.1 q$ & $1.93 \mathrm{~s}$ & 21.1 & $1.94 \mathrm{~s}$ \\
\hline \multicolumn{7}{|l|}{31} \\
\hline \multicolumn{7}{|l|}{32} \\
\hline 33 & & & & & & \\
\hline
\end{tabular}

${ }^{a}$ Exchangeable signals. 
Table 2 (Continued)

\begin{tabular}{|c|c|c|c|c|c|c|}
\hline \multirow{2}{*}{ Position } & \multicolumn{2}{|c|}{ Stemphone E } & \multicolumn{2}{|c|}{ Stemphone F } & \multicolumn{2}{|c|}{ Stemphone G } \\
\hline & $\delta_{\mathrm{C}}$ & $\delta_{\mathrm{H}}(\mathrm{J} \mathrm{Hz})$ & $\delta_{\mathrm{C}}$ & $\delta_{\mathrm{H}}(\mathrm{J} \mathrm{Hz})$ & $\delta_{\mathrm{C}}$ & $\delta_{\mathrm{H}}(\mathrm{JHz})$ \\
\hline 1 & 12.9 & $1.62 \mathrm{~d}(6.0)$ & 13.4 & $1.63 \mathrm{~d}(7.0)$ & 13.4 & $1.62 \mathrm{~d}(7.0)$ \\
\hline 2 & 125.8 & 5.63 q (6.0) & 127.5 & $5.70 q(7.0)$ & 125.6 & $5.64 \mathrm{q}(7.0)$ \\
\hline 3 & 132.5 & - & 131.5 & - & 132.5 & - \\
\hline 4 & 83.1 & $5.34 d(10.0)$ & 83.1 & $5.14 \mathrm{~d}(10.0)$ & 82.5 & $5.36 \mathrm{~d}(10.0)$ \\
\hline 5 & 33.8 & $3.44 \mathrm{dq}(9.0,7.0)$ & 36.2 & $3.00 \mathrm{dq}(10.0,7.0)$ & 36.1 & $3.48 \mathrm{dq}(10.0,7.0)$ \\
\hline 6 & 128.8 & - & 162.0 & - & 140.5 & - \\
\hline 7 & 136.5 & - & 71.9 & - & 135.6 & - \\
\hline 8 & 139.7 & - & 169.1 & - & 144.2 & - \\
\hline 9 & 111.0 & - & 110.1 & - & 107.0 & - \\
\hline 10 & 147.4 & - & 187.5 & - & 133.8 & - \\
\hline $10-\mathrm{OH}$ & & & & & & $10.8 \mathrm{~s}$ \\
\hline 11 & 104.6 & $6.18 \mathrm{~s}$ & 124.1 & $6.06 \mathrm{~s}$ & 107.4 & $6.33 \mathrm{~s}$ \\
\hline 12 & 63.6 & $5.06 \mathrm{~d}(10.0)$ & 62.4 & $\begin{array}{l}4.79 d(10.5) \\
2.52 d d(19.0,5.0)\end{array}$ & 199.5 & - \\
\hline $12-\mathrm{OH}^{\mathrm{a}}$ & - & - & - & - & - & - \\
\hline 13 & 46.5 & $2.32 d(10.0)$ & 46.4 & $2.06 d(10.5)$ & 53.6 & $3.49 \mathrm{~s}$ \\
\hline 14 & 80.4 & - & 83.5 & - & 84.1 & - \\
\hline 15 & 37.6 & $1.88 \mathrm{~m}$ & 37.4 & $1.60,1.96 \mathrm{~m}$ & 37.4 & $2.38 \mathrm{~m}$ \\
\hline 16 & 25.1 & $1.58 \mathrm{~m}, 1.80 \mathrm{~m}$ & 25.2 & $1.58,1.82 \mathrm{~m}$ & 24.9 & $1.66,1.86 \mathrm{~m}$ \\
\hline 17 & 76.6 & $3.70 \mathrm{dd}(13.0,4.0)$ & 76.7 & $3.66 \mathrm{dd}(13.0,4.5)$ & 75.9 & $3.74 \mathrm{dd}(13.0,4.0)$ \\
\hline 18 & $40.8 \mathrm{~s}$ & 40.5 & - & 40.9 & - & $40.3 \quad-$ \\
\hline 19 & $70.7 d$ & 4.14 t br (3.0) & 70.9 & $4.11 \mathrm{t}, \mathrm{br}(3.5)$ & 70.0 & $4.76 \mathrm{t}, \mathrm{br}(3.0)$ \\
\hline $19-\mathrm{OH}^{\mathrm{a}}$ & - & - & - & - & - & - \\
\hline 20 & 28.1 & $1.60 \mathrm{~m}, 1.92 \mathrm{~m}$ & 28.4 & $1.58,1.94 \mathrm{~m}$ & 29.7 & $1.50,2.06 \mathrm{~m}$ \\
\hline 21 & 79.5 & $3.58 \mathrm{dd}(13.0,3.0)$ & 80.0 & $3.56 \mathrm{dd}(13.0,3.0)$ & 79.6 & $3.61 \mathrm{dd}(13.0,3.0)$ \\
\hline 22 & 72.0 & - & 72.1 & - & 72.0 & - \\
\hline 23 & 23.7 & $1.13 \mathrm{~s}$ & 23.8 & $1.13 \mathrm{~s}$ & 24.0 & $1.16 \mathrm{~s}$ \\
\hline 24 & 26.0 & $1.18 \mathrm{~s}$ & 26.5 & $1.18 \mathrm{~s}$ & 26.4 & $1.20 \mathrm{~s}$ \\
\hline 25 & 13.1 & $0.97 \mathrm{~s}$ & 13.3 & $0.95 \mathrm{~s}$ & 13.3 & $1.12 \mathrm{~s}$ \\
\hline 26 & 22.1 & $1.24 \mathrm{~s}$ & 21.8 & $1.28 \mathrm{~s}$ & 22.5 & $1.48 \mathrm{~s}$ \\
\hline 27 & 17.6 & $0.99 \mathrm{~d}(7.5)$ & 20.1 & $0.99 \mathrm{~d}(7.0)$ & 17.0 & $1.09 \mathrm{~d}(7.0)$ \\
\hline 28 & 10.9 & $1.64 \mathrm{~s}$ & 11.1 & $1.61 \mathrm{~s}$ & 11.5 & $1.64 \mathrm{~s}$ \\
\hline 29 & 171.4 & - & 169.4 & - & 170.2 & - \\
\hline 30 & 21.2 & $1.78 \mathrm{~s}$ & 21.3 & $1.94 \mathrm{~s}$ & 21.3 & $1.84 \mathrm{~s}$ \\
\hline \multirow[t]{2}{*}{31} & & & 46.6 & $2.50 \mathrm{~d}(15.5)$ & & \\
\hline & & & & $2.94 d(15.5)$ & & \\
\hline 32 & & & 209.9 & - & & \\
\hline 33 & & & 33.5 & $2.30 \mathrm{~s}$ & & \\
\hline
\end{tabular}

${ }^{a}$ Exchangeable signals. 
while stemphones E, F and G had different patterns in UV absorption. The IR absorption at 3442 2929 and $1735 \sim 1604 \mathrm{~cm}^{-1}$ suggested the presence of hydroxy and carbonyl groups in the structures.

Stemphone D: The molecular formula was determined to be $\mathrm{C}_{30} \mathrm{H}_{42} \mathrm{O}_{8}$ on the basis of HRFAB-MS measurement, indicating that stemphone $\mathrm{D}$ contained one less oxygen atom relative to stemphone $\mathrm{B}$. The ${ }^{13} \mathrm{C}$-NMR spectrum (in $\mathrm{CDCl}_{3}$ ) showed 30 resolved signals, which were classified into eight methyl carbons, four methylene carbons, two $s p^{3}$ methine carbons, two $s p^{2}$ methine carbons, four oxygenated $s p^{3}$ methine carbons, one $s p^{3}$ quaternary carbon, two oxygenated $s p^{3}$ quaternary carbons, four $s p^{2}$ quaternary carbons and three carbonyl carbons by analysis of the DEPT spectra. The ${ }^{1} \mathrm{H}-\mathrm{NMR}$ spectrum (in $\mathrm{CDCl}_{3}$ )

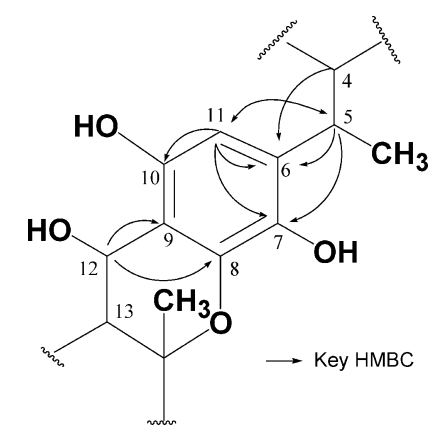

Fig. 4 Key HMBC of stemphone E. displayed 40 proton signals. The connectivity of proton and carbon atoms was established by the ${ }^{13} \mathrm{C}-{ }^{1} \mathrm{H}$ HMQC spectrum (Table 2). These spectral data and physicochemical properties showed that stemphone D has the same skeleton as stemphones B and C [3]. Furthermore, the

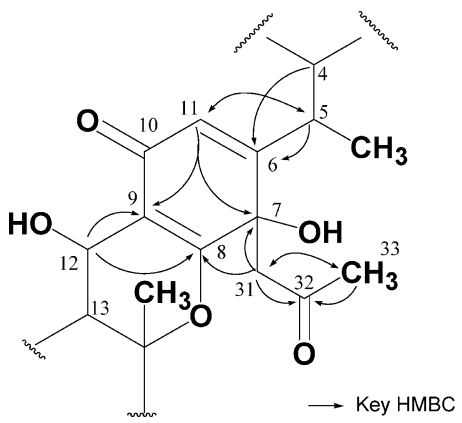

Fig. 5 Key HMBC of stemphone F.

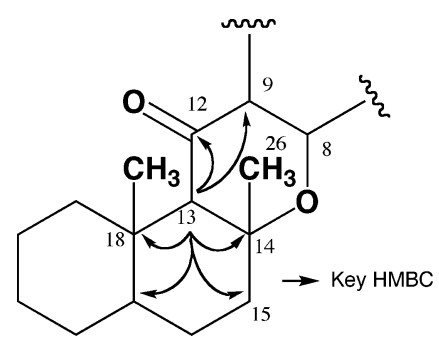

Fig. 6 Key HMBC of stemphone G.<smiles>CC=C(C)C(OC(C)=O)C(C)C1=CC(=O)C2=C(C[C@]3(C)C4(C)CC[C@H](C(C)(C)O)OC4CC[C@@]3(C)O2)C1=O</smiles>

Stemphone C (a)

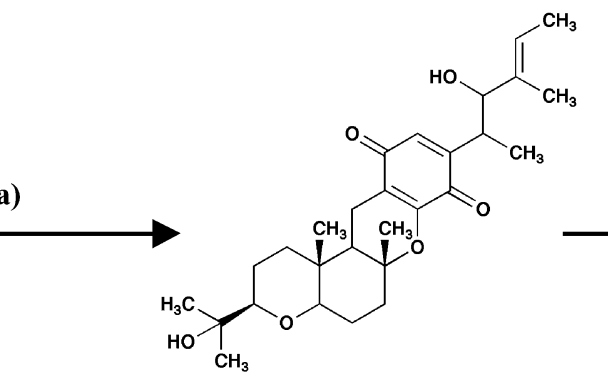

C2 (b)<smiles>[2H]C(=O)OC(/C(C)=C/C)C(C)C1=CC(=O)C2=C(C1=O)[C@]1(C)CCC3O[C@H](C(C)(C)O)CC[C@]3(C)C1CC2</smiles>

C-4 derivatives

(c)

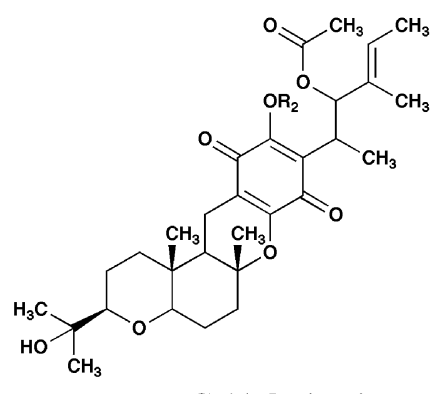

\section{C-11 derivatives}

Scheme 1 Semisynthetic strategy for stemphone C-4 and C-11 derivatives. (a) $\mathrm{LiAlH}_{4}, \mathrm{Et}_{2} \mathrm{O}, 0^{\circ} \mathrm{C}$; (b) $\left(\mathrm{R}_{1} \mathrm{CO}\right)_{2} \mathrm{O}$, DMAP, TEA, $\mathrm{CH}_{2} \mathrm{Cl}_{2}$; (c) $\mathrm{R}_{2} \mathrm{OH}$, DMAP, pyridine, $60^{\circ} \mathrm{C}$. 
methylene proton signals $(\delta 2.12,2.50)$ were observed instead of the methine proton signal of $\mathrm{H}-12(\delta 4.90)$ of stemphone $\mathrm{B}$, indicating that stemphone $\mathrm{D}$ is 12-dehydroxy stemphone $\mathrm{B}$. Thus, the structure of stemphone $\mathrm{D}$ was elucidated as shown in Fig. 1.

Stemphone E: The molecular formula of stemphone E is $\mathrm{C}_{30} \mathrm{H}_{44} \mathrm{O}_{9}$, indicating that two hydrogen atoms are bigger than stemphone B. The ${ }^{1} \mathrm{H}-\mathrm{NMR}$ spectrum of stemphone $\mathrm{E}$ was almost identical to that of stemphone B except for the absence of the quinone carbonyl signals in stemphone $\mathrm{E}$. Instead, five quaternary carbons $(\delta 111.2,128.8,136.5$, $139.7,147.4)$ and one methine carbon $(\delta$ 104.6) were observed, indicating the presence of a quinol residue instead of a quinone residue. This was also supported by the physico-chemical properties of the UV absorption $(292 \mathrm{~nm})$ and the appearance (white powder) (Table 1) [5]. Furthermore, the ${ }^{13} \mathrm{C}-{ }^{1} \mathrm{H}$ long range couplings of ${ }^{2} J$ and ${ }^{3} J$ in the ${ }^{13} \mathrm{C}-{ }^{1} \mathrm{H}$ HMBC spectrum revealed the following linkage of quinol carbons (Fig. 4). The cross peaks were observed from H-5 ( $\delta 3.44)$ to C-6 $(\delta 128.8), \mathrm{C}-7(\delta 136.5)$ and $\mathrm{C}-11(\delta 104.6)$, from H-11 $(\delta 6.18)$ to $\mathrm{C}-6, \mathrm{C}-7$ and C$9(\delta 111.0)$, and from H-12 $(\delta 5.06)$ to C-8 $(\delta 139.7), \mathrm{C}-9$ and $\mathrm{C}-10(\delta$ 147.4). The chemical shifts of the quinol moiety for stemphone $\mathrm{E}$ were comparable to that of isocochlioquinone A [6]. Taken together, the structure of stemphone E was elucidated as shown in Fig. 1.

Stemphone F: The molecular formula of stemphone $F$ is $\mathrm{C}_{33} \mathrm{H}_{48} \mathrm{O}_{10}$. The ${ }^{1} \mathrm{H}-\mathrm{NMR}$ spectrum was similar to that of stemphone B except for the presence of a methyl proton signal $(\delta 2.30)$ and methylene proton signals $(\delta 2.50,2.94)$ in stemphone F. Moreover, the signals of a methyl carbon ( $\delta$ $33.5)$, a methylene carbon ( $\delta 46.6)$, an oxyquaternary carbon $(\delta 71.9)$ and a carbonyl carbon $(\delta 209.9)$ were newly observed by the analysis of the ${ }^{13} \mathrm{C}-\mathrm{NMR}$ spectrum instead of the absence of a quinone carbonyl carbon (C-7) in stemphone B. Furthermore, ${ }^{13} \mathrm{C}-{ }^{1} \mathrm{H}$ HMBC experiments gave the following linkage (Fig. 5). The cross peaks were observed from $\mathrm{H}-33(\delta 2.30)$ to $\mathrm{C}-31(\delta 46.6)$ and $\mathrm{C}-32(\delta$ $209.9)$, and from $\mathrm{H}-31(\delta 2.50,2.94)$ to $\mathrm{C}-7$ and $\mathrm{C}-8$, indicating that a propanone residue was attached to the $\mathrm{C}-7$ position. And the chemical shift of C-7 ( $\delta 71.9)$ showed that a hydroxyl group was also attached to this position. Furthermore, the chemical shifts of stemphone $\mathrm{F}$ were comparable to those of cochlioquinol II [7]. Taken together, stemphone $\mathrm{F}$ was elucidated as shown in Fig. 1.

Stemphone G: The molecular formula is $\mathrm{C}_{30} \mathrm{H}_{42} \mathrm{O}_{9}$, indicating that two hydrogen atoms were smaller than stemphone E. The ${ }^{1} \mathrm{H}-\mathrm{NMR}$ spectrum of stemphone $\mathrm{G}$ resembled that of stemphone $\mathrm{E}$ except that the methine proton $(\delta$ 5.06) in stemphone $\mathrm{E}$ was not observed. Accordingly, a carbonyl carbon signal ( $\delta$ 199.5) was
Table 3 MIC of imipenem against MRSA in the presence of stemphones and cytotoxic effect of stemphones on Jurkat cells $[3,5]$

\begin{tabular}{|c|c|c|c|}
\hline $\begin{array}{l}\text { In combination } \\
\text { with }\end{array}$ & $\begin{array}{l}\text { MIC of IPM } \\
(\mathrm{ng} / \mathrm{ml})\end{array}$ & $\begin{array}{l}\text { Potentiation Ratio } \\
\text { (None/stemphone) }\end{array}$ & $\begin{array}{c}\mathrm{IC}_{50} \\
(\mu \mathrm{g} / \mathrm{ml})\end{array}$ \\
\hline None & 16000 & 1 & - \\
\hline Stemphone B & 30 & 533 & 2.13 \\
\hline C & 30 & 533 & 0.43 \\
\hline $\mathrm{C} 1 \mathrm{a}$ & 1000 & 16 & 13.7 \\
\hline $\mathrm{C} 1 \mathrm{~b}$ & 16000 & 1 & 5.75 \\
\hline $\mathrm{C} 1 \mathrm{c}$ & 16000 & 1 & 8.51 \\
\hline $\mathrm{C} 1 \mathrm{~d}$ & 2000 & 8 & 16.2 \\
\hline $\mathrm{C} 1 \mathrm{e}$ & 16000 & 1 & 9.12 \\
\hline $\mathrm{C} 1 \mathrm{f}$ & 16000 & 1 & 12.2 \\
\hline $\mathrm{C} 1 \mathrm{~g}$ & 16000 & 1 & 20.6 \\
\hline $\mathrm{C} 1 \mathrm{~h}$ & 1000 & 16 & 15.1 \\
\hline $\mathrm{C} 1 \mathrm{i}$ & 16000 & 1 & 2.82 \\
\hline $\mathrm{C} 2$ & 60 & 266 & 0.78 \\
\hline С3a & 60 & 266 & 0.50 \\
\hline $\mathrm{C} 3 \mathrm{~b}$ & 60 & 266 & 1.35 \\
\hline $\mathrm{C} 3 \mathrm{c}$ & 250 & 64 & 1.50 \\
\hline C3d & 16000 & 1 & 0.56 \\
\hline $\mathrm{C} 3 \mathrm{e}$ & 250 & 64 & 0.95 \\
\hline $\mathrm{C} 4$ & 16000 & 1 & 34.8 \\
\hline D & 60 & 266 & 1.81 \\
\hline E & 30 & 533 & 3.64 \\
\hline E1 & 4000 & 4 & 26.2 \\
\hline E2 & 30 & 533 & 4.44 \\
\hline E3 & 30 & 533 & 0.59 \\
\hline E4 & 16000 & 1 & $>100$ \\
\hline F & 60 & 266 & 2.69 \\
\hline G & 16000 & 1 & 23.7 \\
\hline $\mathrm{G} 1$ & 16000 & 1 & $>100$ \\
\hline Cochlioquinone D & 8000 & 2 & 0.070 \\
\hline
\end{tabular}

Concentration of stemphones is $4.0 \mu \mathrm{g} / \mathrm{ml}$. IPM, imipenem.

observed in stemphone $\mathrm{G}$ instead of the $\mathrm{C}-12$ methine carbon of stemphone $\mathrm{E}$, showing the presence of an oxo residue at $\mathrm{C}-12$ in stemphone G. Furthermore, cross peaks were observed from H-13 $(\delta 3.49)$ to $\mathrm{C}-9(\delta 107.0), \mathrm{C}-12$ $(\delta$ 199.5), C-14 ( $\delta$ 84.1), C-15 ( $\delta 37.4), \mathrm{C}-17(\delta 75.9)$ and $\mathrm{C}-18(\delta \quad 40.3)$ by the analysis of ${ }^{13} \mathrm{C}-{ }^{1} \mathrm{H}$ HMBC experiments (Fig. 6), revealing that an oxo residue was attached to the $\mathrm{C}-12$ position. In addition, a low field of the hydroxy proton signal $(\delta 10.8)$ in the ${ }^{1} \mathrm{H}-\mathrm{NMR}$ spectrum indicated a hydrogen bond between the $\mathrm{C}-12$ carbonyl oxygen and the $\mathrm{H}-10$ hydroxy proton. Taken together, these data indicated that stemphone $\mathrm{G}$ was 12 -oxo stemphone $\mathrm{E}$ as shown in Fig. 1. 


\section{Synthesis of Stemphone Derivatives}

Semisynthetic strategy for C-4 and C-11 derivatives is summarized in Scheme 1.

Stemphone C-4 derivatives: First, reduction of the acetyl residue at C-4 of stemphone $\mathrm{C}$ with $\mathrm{LiAlH}_{4}$ yielded stemphone $\mathrm{C} 2$ at $42.2 \%$. Then, stemphone $\mathrm{C} 2$ was acylated with corresponding anhydrous acids to give stemphones C3a (44.9\%), C3b (41.3\%), C3c (46.6\%), C3d (22.4\%) and $\mathrm{C} 3 \mathrm{e}(37.7 \%)$.

Stemphone C-11 derivatives: Stemphone C was treated with methanol and TEA to yield stemphone C1a (40.4\%). Similarly, stemphone $\mathrm{C}$ was treated with corresponding alcohols and DMAP in pyridine to afford C1b (35.6\%), C1c (29.9\%), C1d (17.7\%), C1e (17.5\%), C1f (2.11\%), $\mathrm{C} 1 \mathrm{~g}(24.9 \%)$ and $\mathrm{C} 1 \mathrm{i}(53.0 \%)$.

\section{Potentiation of Imipenem Activity against MRSA by Stemphones}

By the paper disk assay, stemphones and the derivatives alone showed almost no anti-MRSA activity at least up to $50 \mu \mathrm{g} / 6 \mathrm{~mm}$ disk as well as stemphones B and C. However, stemphones D, E, E1, E2, E3, F, C2, C3a, C3b and C3c showed anti-MRSA activity on the MHA plate containing imipenem $(10 \mu \mathrm{g} / \mathrm{ml})$ with an inhibition zone of $25,22,15$, $22,20,20,20,16,16$ and $17 \mathrm{~mm}$ at $10 \mu \mathrm{g} / 6 \mathrm{~mm}$ disk, respectively. Under the same conditions, stemphones B and $\mathrm{C}$ showed anti-MRSA activity with an inhibition zone of 20 and $22 \mathrm{~mm}$ as reported previously [3]. Thus, the findings indicate that these stemphones potentiated the imipenem activity against MRSA. Cochlioquinone D and stemphones $\mathrm{C} 1 \mathrm{~h}$ and $\mathrm{C} 3 \mathrm{e}$ seemed to be weak potentiators with an inhibition zone of $10 \mathrm{~mm}$. On the other hand, the other stemphones showed almost no potentiating activity with no inhibition zone on the MHA plate containing imipenem.

Next, the potentiating activity of all stemphones was confirmed by the liquid microdilution method. First, antiMRSA activity of these stemphones alone was studied by this method. Their MIC values were calculated to be over $16 \mu \mathrm{g} / \mathrm{ml}$ ( $c f$. MIC of stemphone $\mathrm{C}$ is $16 \mu \mathrm{g} / \mathrm{ml}$ [3]). Therefore, the concentrations of stemphones were set up at $4.0 \mu \mathrm{g} / \mathrm{ml}$ to test the potentiation activity. The results of potentiation of imipenem activity against MRSA by the stemphones are summarized in Table 3. As previously reported [3], stemphones $\mathrm{B}$ and $\mathrm{C}$ enhanced the imipenem activity over 500-fold. Stemphones D, E, E2, E3, F, C2, $\mathrm{C} 3 \mathrm{a}$ and $\mathrm{C} 3 \mathrm{~b}$ showed almost the same potentiating activity as stemphones B and C (266 533 folds) followed by stemphones C3c and C3e (64 folds). Stemphones C1a, C1d and $\mathrm{C} 1 \mathrm{~h}$ were moderate potentiators $(8 \sim 16$-fold). The 12 other compounds had almost no potentiating activity. These data are fundamentally comparable to those obtained from the paper disk method as described above.

\section{Cytotoxicity against Jurkat Cells}

Cytotoxic effect of all stemphones on Jurakat cells is summarized in Table 3. Among them, cochlioquinone D

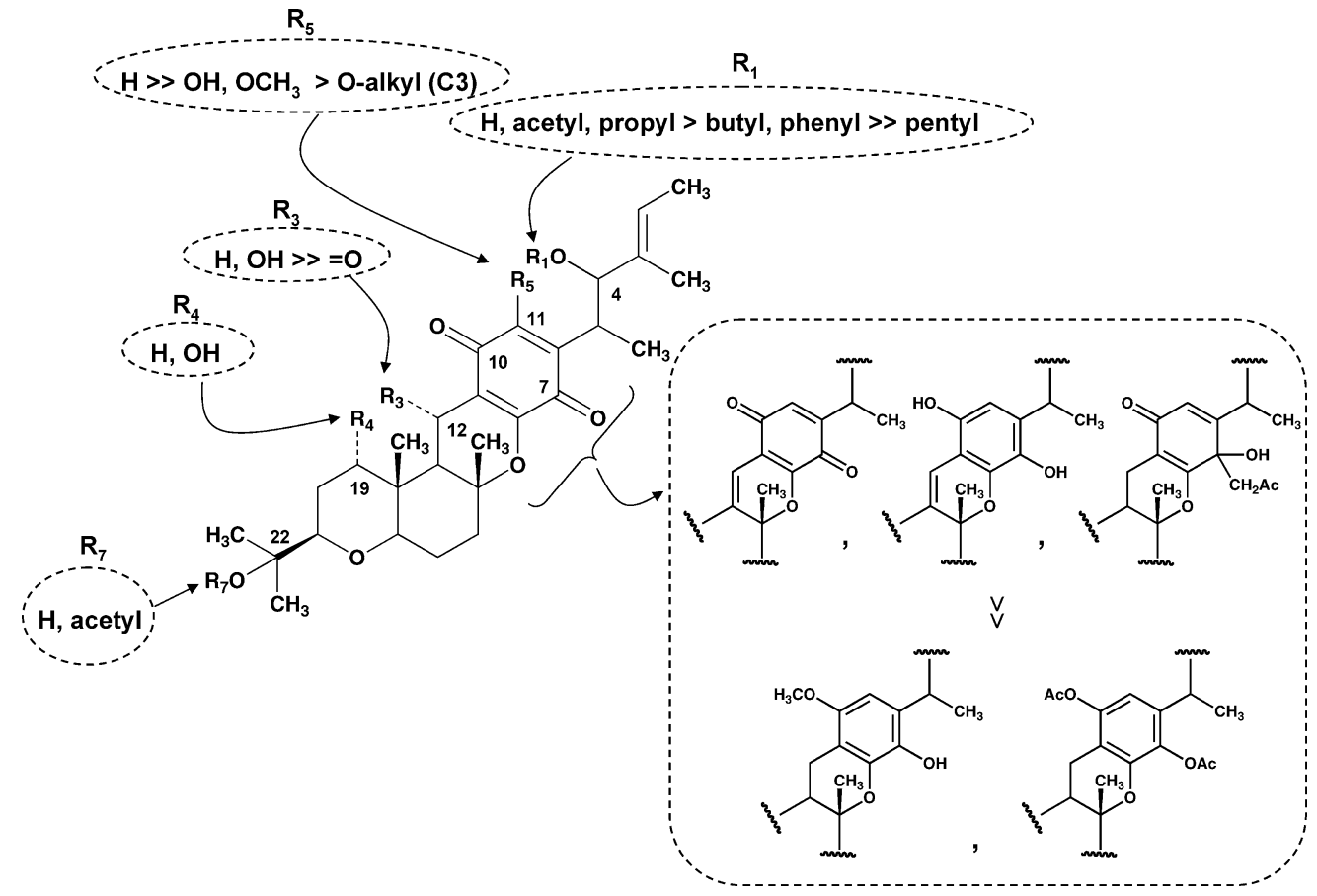

Fig. 7 Summary of structure-activity relationships. 
showed the most potent cytotoxicity with an $\mathrm{IC}_{50}$ of $0.070 \mu \mathrm{g} / \mathrm{ml}$, while stemphones E1 and G1 had almost no cytotoxicity $\left(\mathrm{IC}_{50}>100 \mu \mathrm{g} / \mathrm{ml}\right)$. Stemphones B, E, E2 and E3 showed moderate cytotoxicity $\left(\mathrm{IC}_{50}, 2.13 \sim 4.44 \mu \mathrm{g} / \mathrm{ml}\right)$ and the strongest potentiation of imipenem activity against MRSA (533 folds, Table 3).

\section{Discussion}

Seven structurally related compounds including six new stemphones $\mathrm{B}$ to $\mathrm{G}$ and known cochlioquinone $\mathrm{D}$ were isolated from the culture broth of Aspergillus sp. FKI-2136, but stemphone (stemphone A) itself was not detected and isolated from the culture. Since stemphone $F$ has a propanone residue in the structure, it is plausible that stemphone $\mathrm{F}$ is produced by the treatment of stemphone $\mathrm{B}$ with acetone. However, no product was obtained by the treatment of stemphone B with acetone.

Compounds structurally related to stemphones and cochlioquinones have various biological activities [8 10]. As previously reported, we found a new biological activity, namely an activity potentiating the $\beta$-lactam imipenem activity against MRSA [3]. In this study, the potentiating activity of all the stemphones (natural and semisynthetic ones) was tested to investigate the structure-activity relationships (Fig. 7). Regarding the $\mathrm{C}-4$ position $\left(\mathrm{R}_{1}\right), O$ acyl derivatives with a $\mathrm{C} 2$ to $\mathrm{C} 5$ carbon length retained the potentiating activity, but derivatives with a longer acyl residue drastically decreased the activity, indicating that the moderate lipophilicity at C-4 is important for the activity. Regarding the C-11 position $\left(\mathrm{R}_{5}\right)$, introduction of most $O$ alkyl residues resulted in a decrease of the activity. Only hydroxy and $O$-methyl showed very weak activity. Thus, no modification at this position is preferable for the potentiating activity. Furthermore, regarding the 7,10quinone part, it is replaceable by 7,10-hydroquinone or 7hydroxy-7-propanone-10-oxo. However, activity was lost when a methyl or acetyl residue was introduced to the $\mathrm{C}-10$ hydroxy group. Regarding the C-12 ( $\left.\mathrm{R}_{3}\right)$ and C-19 $\left(\mathrm{R}_{4}\right)$ positions, the potentiating activity was retained regardless of introduction of a hydroxy residue in these positions. Among these stemphones, it was concluded that stemphone $\mathrm{E}$ is the most selective compound, showing the most potent potentiation of imipenem activity against MRSA (533-fold) and the lowest cytotoxic activity against Jurkat cells. This information about the structure-activity relationships would lead to a new type of anti-infective agent as an imipenem potentiator against MRSA.

Several natural products have previously been reported to potentiate $\beta$-lactam activity against MRSA [11 16], possibly due to inhibition of penicillin-binding proteins 2 (PBP2') and suppression of $\beta$-lactamase activity. Our preliminary experiments on the mechanism of action suggested that stemphones showed almost no effect on PBP2' (data not shown). The mechanism of the potentiating activity by stemphones remains to be determined. This study on the structure-activity relationships of stemphones could be useful for preparing a probe to analyze the target molecule. Further investigations on the mechanism of action are now in progress.

Acknowledgments This study was supported in part by the grant of Kakenhi 19710191, Ministry of Education, Culture, Sports, Science and Technology, Japan. We thank Mr. Ohtawa for useful discussion and valuable advice. We express our thanks to Ms. N. Sato for NMR experiments, Ms. T. Sakabe and Ms. A. Nakagawa for mass spectra.

\section{References}

1. Hiramatsu K, Hanaki H, Ino T, Yabuta K, Oguri T, Tenover FC. Methicillin-resistant Staphylococcus aureus clinical strain with reduced vancomycin susceptibility. J Antimicrob Chemother 40: 135-136 (1997)

2. Centers for Disease Control and Prevention. Staphylococcus aureus with reduced susceptibility to vancomycin-United States, 1997. MMWR Morb Mortal Wkly Rep 46: 765-766 (1997)

3. Koyama N, Nagahiro T, Yamaguchi Y, Masuma R, Tomoda H, Ömura S. Stemphones, novel potentiators of imipenem activity against methicillin-resistant Staphylococcus aureus, produced by Aspergillus sp. FKI-2136. J Antibiot 58: 695-703 (2005)

4. Schnur RC, Corman ML, Gallaschun RJ, Cooper BA, Dee MF, Doty JL, Muzzi ML, DiOrio CI, Barbacci EG, Miller PE, Pollack VA, Savage DM, Sloan DE, Pustilnik LR, Moyer JD, Moyer MP. erbB-2 oncogene inhibition by geldanamycin derivatives: synthesis, mechanism of action, and structure-activity relationships. J Med Chem 38: 3813-3820 (1995)

5. Mosmann T. Rapid colorimetric assay for cellular growth and survival: application to proliferation and cytotoxicity assays. J Immunol Methods 65: 55-63 (1983)

6. Miyagawa H, Nagai S, Tsurushima T, Sato M, Ueno T, Fukami H. Phytotoxins produced by the plant pathogenic fungus Bipolaris bicolor El-1. Biosci Biotech Biochem 58: 1143-1145 (1994)

7. Lim CH, Miyagawa H, Ueno T, Takenaka H, Tsurusima T. Isolation and structure elucidation of terpenoid phytotoxins produced by the plant pathogenic fungus Bipolaris cynodontis. Tennen Yuki Kagobutsu Toronkai Koen Yoshishu 37th: 325-330 (1995)

8. Schaeffer JM, Frazier EG, Bergstrom AR, Williamson JM, 
Liesch JM, Goetz MA. Cochlioquinone A, a nematocidal agent which competes for specific $\left[{ }^{3} \mathrm{H}\right]$ ivermectin binding sites. J Antibiot 43: 1179-1182 (1990)

9. Lee HB, Lim CH, Kwon HJ, Kim YK, Lee HS, Kim CJ. Inhibitory activity of diacylglycerol acyltransferase by cochlioquinones A and A1. J Antibiot 56: 967-969 (2003)

10. Fujioka T, Yao K, Hamano K, Hosoya T, Kagasaki T, Furukawa Y, Haruyama H, Sato S, Koga T, Tsujita Y. Epi-cochlioquinone A, a novel acyl-CoA:cholesterol acyltransferase inhibitor produced by Stachybotrys bisbyi. J Antibiot 49: 409-413 (1996)

11. Zhao WH, Hu ZQ, Okubo S, Hara Y, Shimamura T. Mechanism of synergy between epigallocatechin gallate and beta-lactams against methicillin-resistant Staphylococcus aureus. Antimicrob Agents Chemother 45: 1737-1742 (2001)

12. Shimizu M, Shiota S, Mizushima T, Ito H, Hatano T, Yoshida T, Tsuchiya T. Marked potentiation of activity of beta-lactams against methicillin-resistant Staphylococcus aureus by corilagin. Antimicrob Agents Chemother 45: 3198-3201 (2001)
13. Shiota S, Shimizu M, Mizushima T, Ito H, Hatano T, Yoshida T, Tsuchiya T. Restoration of effectiveness of betalactams on methicillin-resistant Staphylococcus aureus by tellimagrandin I from rose red. FEMS Microbiol Lett 185: 135-138 (2000)

14. Shiota S, Shimizu M, Sugiyama J, Morita Y, Mizushima T, Tsuchiya T. Mechanisms of action of corilagin and tellimagrandin I that remarkably potentiate the activity of beta-lactams against methicillin-resistant Staphylococcus aureus. Microbiol Immunol 48: 67-73 (2004)

15. Fukumoto A, Kim Y-P, Matsumoto A, Takahashi Y, Shiomi K, Tomoda H, Ōmura S. Cyslabdan, a new potentiator of imipenem activity against methicillin-resistant Staphylococcus aureus, produced by Streptomyces sp. K040144. I. Taxonomy, fermentation, isolation and structural elucidation. J Antibiot 61: 1-6 (2008)

16. Fukumoto A, Kim Y-P, Hanaki H, Shiomi K, Tomoda H, Ōmura S. Cyslabdan, a new potentiator of imipenem activity against methicillin-resistant Staphylococcus aureus, produced by Streptomyces sp. K04-0144. II. Biological activities. J Antibiot 61: 7-10 (2008) 